\title{
Complex Genetic Control of HDL Levels in Mice in Response to an Atherogenic Diet

\author{
Coordinate Regulation of HDL Levels and Bile Acid Metabolism
}

\author{
Dietrich Machleder, ${ }^{*}$ Boris Ivandic, ${ }^{*}$ Carrie Welch, ${ }^{*}$ Lawrence Castellani, ${ }^{*}$ Karen Reue, ${ }^{\ddagger}$ and Aldons J. Lusis ${ }^{\star}$ \\ *Department of Medicine, Department of Microbiology and Molecular Genetics, and Molecular Biology Institute, University of \\ California, Los Angeles, Los Angeles, California 90095; and ${ }^{\ddagger}$ Lipid Research Group, Wadsworth VA Medical Center, Wilshire and \\ Sawtelle Blvds. Los Angeles, California 90073
}

\begin{abstract}
Inbred strains of mice differ in susceptibility to atherogenesis when challenged with a high fat, high cholesterol diet containing $0.5 \%$ cholic acid. Studies of recombinant inbred (RI) strains derived from the susceptible strain C57BL/6J (B6) and the resistant strains $\mathrm{C} 3 \mathrm{H} / \mathrm{HeJ}(\mathrm{C} 3 \mathrm{H})$ and $\mathrm{BALB} / \mathrm{cJ}$ have revealed an association between fatty streak lesion size and a decrease in high density lipoprotein (HDL) levels on the diet. To better understand the genetic factors contributing to HDL metabolism and atherogenesis in response to the diet, we studied mice derived from an intercross between B6 and $\mathrm{C} 3 \mathrm{H}$ using a complete linkage map approach. A total of 185 female progeny were typed for $\mathbf{1 3 4}$ genetic markers spanning the mouse genome, resulting in an average interval of about $10 \mathrm{cM}$ between markers. A locus on distal chromosome 1 containing the apolipoprotein AII gene was linked to HDL-cholesterol levels on both the chow and the atherogenic diets, but this locus did not contribute to the decrease in HDL-cholesterol in response to the diet. At least three distinct genetic loci, on chromosomes 3,5 , and 11, exhibited evidence of linkage to a decrease in HDL-cholesterol after a dietary challenge. Since a bile acid (cholic acid) is required for the diet induced changes in HDL levels and for atherogenesis in these strains, we examined cholesterol-7-alpha hydroxylase $(\mathrm{C} 7 \mathrm{AH})$ expression. Whereas B6 mice exhibited a large decrease in $\mathrm{C} 7 \mathrm{AH}$ mRNA levels in response to the diet, $\mathrm{C} 3 \mathrm{H}$ showed an increase. Among the intercross mice, multiple loci contributed to the regulation of $\mathrm{C} 7 \mathrm{AH}$ mRNA levels in response to the diet, the most notable of which coincided with the loci on chromosomes 3,5 , and 11 controlling HDL levels in response to the diet. None of these loci were linked to the C7AH structural gene which we mapped to proximal chromosome 4 . These studies reveal coordinate regulation of $\mathrm{C} 7 \mathrm{AH}$ expression and HDL levels, and they indicate that the genetic factors controlling HDL levels are more complex than previously suggested by studies of RI strains. Furthermore, we observed that two of the loci for $\mathrm{C} 7 \mathrm{AH}$ expression contributed to differences in gall-
\end{abstract}

Address correspondence to Aldons J. Lusis, Department of Medicine/Division of Cardiology, 47-123 Center of Health Sciences, UCLA, Los Angeles, CA 90095-1679. Phone: 310-825-1359; FAX: 310-794-7345.

Received for publication 29 July 1996 and accepted in revised form 17 December 1996.

J. Clin. Invest.

(C) The American Society for Clinical Investigation, Inc. 0021-9738/97/03/1406/14 \$2.00

Volume 99, Number 6, March 1997, 1406-1419 stone formation between these strains. (J. Clin. Invest. 1997. 99:1406-1419.) Key words: Ath-1 • cholesterol-7-alpha hydroxylase $\bullet$ linkage analysis $\bullet$ quantitative trait loci $\bullet$ cholic acid $\bullet$ aortic fatty streak lesions

\section{Introduction}

Inbred strains of mice show striking differences in aortic fatty streak development in response to high fat, high cholesterol diet, and genetic studies have suggested the existence of major genes contributing to these differences (1-5). Because the nongenetic variation of aortic lesion size is quite large, such studies have been largely restricted to analysis of recombinant inbred $(\mathrm{RI})^{1}$ strains, which allow multiple animals of a single recombinant genotype to be examined (2). The first such study to be reported involved analysis of RI strains derived from crosses between strain $\mathrm{C} 57 \mathrm{BL} / 6 \mathrm{~J}$ (B6) (susceptible to diet induced atherosclerosis) and either $\mathrm{C} 3 \mathrm{H} / \mathrm{HeJ}(\mathrm{C} 3 \mathrm{H})$ or $\mathrm{BALB} / \mathrm{cJ}$ (resistant) (1). The parental and RI strains were studied for the size of aortic lesions and the levels of plasma lipoproteins after feeding of the atherogenic diet for a period of $15 \mathrm{wk}$. The results indicated that the HDL-cholesterol levels among the RI strains were inversely correlated with aortic lesion development, consistent with human epidemiological studies indicating an inverse correlation between HDL-cholesterol levels and incidence of coronary heart disease. Moreover, the distribution among the RI strains of HDL-cholesterol levels on the atherogenic diet was consistent with a major gene linked to, but not identical with, the apoAII gene in distal mouse chromosome 1. This gene was designated Ath-1 (for atherosclerosis-1). A number of additional loci contributing to aortic lesion development have subsequently been tentatively mapped in studies of recombinant inbred strains derived from other parental strains (3-5), but as yet, none of the underlying genes has been identified.

To further examine the genetic control of atherosclerosis and HDL metabolism in the mouse model, we now report analyses of a large F2 intercross between susceptible B6 mice and resistant $\mathrm{C} 3 \mathrm{H}$ mice. Quantitative trait locus (QTL) mapping confirmed the presence of a major locus contributing to HDL cholesterol levels on distal chromosome 1, but this locus was explained by a genetic difference in the apoAII gene, resulting in altered apoAII synthesis, that determined HDL-cholesterol levels on both the chow and high fat diets rather than dietary responsiveness. The decrease in HDL-cholesterol observed in $\mathrm{B} 6$, but not $\mathrm{C} 3 \mathrm{H}$, mice in response to the atherogenic diet was controlled by multiple loci on separate chromosomes. At least three of these loci were associated with differences in

1. Abbreviations used in this paper: QTL, quantitative trait locus; RI, recombinant inbred. 
the expression of cholesterol-7-alpha hydroxylase $(\mathrm{C} 7 \mathrm{AH})$, indicating a genetic link between bile acid synthesis and HDLcholesterol levels. Our results suggest that the control of HDLcholesterol levels and atherogenesis in this mouse model is multigenic rather than being due to a single major gene.

\section{Methods}

Mice and diets. All mice were obtained from The Jackson Laboratory (Bar Harbor, ME). An F2 intercross between male C3H and female B6 inbred strains was constructed and only female progeny $(n=$ $185)$ were used because male mice are less susceptible to atherogenesis than female mice and because use of both sexes would introduce an additional variable. All animals were maintained in a relatively pathogen-free environment on a 12-h light:dark cycle with free access to water and food. The animals were fed a chow diet (Purina 5001 chow) which contains $4.5 \%$ fat until 3 mo of age, when they were bled after a 15-h fast. They were then placed on an atherogenic diet (1), containing $30 \%$ of calories as fat and, by weight, $15 \%$ total fat $(8 \%$ cocoa butter), $1.25 \%$ cholesterol, and $0.5 \%$ cholic acid (Teklad 90221 , Teklad Premier Laboratory Diet, Madison, WI), for at least 3 wk, after which plasma lipid levels did not change (6).

Lipoprotein measurements. Plasma total cholesterol, combined low density lipoprotein cholesterol (LDL-C) plus very low density lipoprotein cholesterol (VLDL-C), and HDL cholesterol concentrations were determined as previously described (7). Fast Performance Liquid Chromatography (Pharmacia Biotech, Piscataway, NJ) was performed as described (7).

C7AH expression. C7AH mRNA levels in the inbred strains were measured using the Riboprobe Protection Assay (Ambion, Austin, TX). The mouse RNA probe was synthesized using a PCRderived mouse sequence subcloned into the Sma1 site of the pGem-2 vector (Promega Corp., Madison, WI). This allowed transcription of the complimentary sequence of the mouse C7AH mRNA that corresponds to the rat $\mathrm{C} 7 \mathrm{AH}$ sequence between nucleotides 259 and 587 (8). The sequence of the clone from the T7 promoter to the SP6 promoter was 5'-AACTCCCTGTCATACCACAAAGGTCTTATGTCACGGAAAATATTTTTGACTGGAAAAAATTTCATTACACTACTTCTGCGAATTCATTTGGACACAGAAGCATAAGACCAAAGTGATGGAAATACCACGGAAAACATAAACAAGACTTTTAACAAAACCCTCCATGGAGATGCTCTGTGTTCACTCTCTCTGAAGCCATGATGCAAAAACCTCCTAATCTGTCATGAGACCTCCGGGCCTTCCTAAATCAAAGAGCGCTGTCTGGGTC-3'. Total mouse liver RNA was allowed to hybridize at $45^{\circ} \mathrm{C}$ in solution to an excess of a $278 \mathrm{bp}{ }^{32} \mathrm{P}$-labeled riboprobe followed by digestion with RNase. After RNase treatment, products were resolved on 5\% acrylamide, $8 \mathrm{M}$ urea sequencing gels. The protected probe fragment was quantitated using densitometry after a 2-wk exposure on film using Sci Scan 5000 (Beckman Instruments Inc., Fullerton, CA) and values were normalized to the density values for a protected actin probe as indicated by the manufacturer. The actin probe template was supplied in the RPAII Ribonuclease Protection Assay Kit (Ambion Inc.). The levels of $\mathrm{C} 7 \mathrm{AH}$ mRNA in the livers of the $\mathrm{B} 6 \times \mathrm{C} 3 \mathrm{H} \mathrm{F} 2$ progeny were measured using Northern blot analysis using the same riboprobe with hybridization at $72^{\circ} \mathrm{C}$. Measurements were taken using a PhosphorImager (Molecular Dynamics, Sunnyvale, CA). The values were normalized to ribosomal $18 \mathrm{~S}$ RNA values and blots normalized to $\mathrm{C} 7 \mathrm{AH}$ standards on each blot.

Gallstone mass. Gallstones were solubilized as described (9) using a 80:20 cocktail by volume of $N, N$-dimethylformamide and dimethyl sulfoxide. The volume necessary to dissolve the stones was extrapolated as described (9). Ten microliters of the solubilized gallstone powder mix was assayed for cholesterol. Gallstones were also evaluated by visual inspection of the bile for the number and size. A value of 0 was given if no stones were visible, a value of 1 for a few small stones, a value of 2 for many small stones, 3 for a few large stones, and 4 for numerous large stones.
Quantitative trait locus (QTL) mapping. Microsatellite markers were typed as previously described (10-12). Linkage and QTL analysis were performed using the Map Manager v $2.6(13,14)$, and MAPMAKER/EXP 3.0 programs (15). The results were expressed as lod scores, which provide a measure of the strength of evidence for the existence of a genetic locus contributing to a trait. To define a lod score threshold of significance specific for each trait, allowing for an overall experimentwise type 1 error of 0.05 ( $95 \%$ confidence), 1,000 new sets of trait data were derived from the original data set by permutation for each trait. This was accomplished using the Map Manager QT program which randomly shuffles the original data set (16). The maximal peak lod score of each permuted trait analysis was determined and the 95th percentile of the distribution of the peak lod scores for the 1,000 permutations was defined as the lod score threshold. Thus, in a whole genome scan for a particular trait, the likelihood of exceeding this threshold falsely is equal to 0.05 .

Chromosomal mapping of C7AH gene. Linkage analysis of a backcross between B6 and Mus spretus, with B6 as the recurrent parent, was utilized to map the $\mathrm{C} 7 \mathrm{AH}$ gene. Restriction fragment length variants for the C7AH gene were identified by digesting DNA from the parental strains with a variety of restriction enzymes followed by Southern hybridization. Blots were hybridized with a rat $\mathrm{C} 7 \mathrm{AH}$ probe (8) at $55^{\circ} \mathrm{C}$ and washed in $0.2 \times \mathrm{SSC}$ at $55^{\circ} \mathrm{C}$ for $20 \mathrm{~min}$. The segregation pattern of an HindIII restriction fragment length variant was compared to the segregation pattern of 323 markers previously typed in this backcross (17). Linkage was detected using Map Manager v2.6.5 and loci were ordered by minimizing the number of recombination events $(13,14)$.

\section{Results}

Genetic-dietary interactions contributing to plasma lipoprotein levels in female B6, C3H, and F2 intercross mice. The levels of plasma lipoproteins in strain $\mathrm{B} 6$ and $\mathrm{C} 3 \mathrm{H}$ mice fed either a chow or an atherogenic diet were examined by heparin fractionation (Table I) and gel filtration chromatography (Fig. 1). The results were consistent with previous studies $(1,6,18)$. In both $\mathrm{B} 6$ and $\mathrm{C} 3 \mathrm{H}$ mice the levels of LDL/VLDL cholesterol increased dramatically in response to the atherogenic diet. On both diets strain B6 mice exhibited slightly higher LDL/VLDL levels than strain $\mathrm{C} 3 \mathrm{H}$ mice. The strains differed markedly in HDL levels, particularly in the change in HDL levels in response to the dietary challenge. Thus, on the chow diet $\mathrm{C} 3 \mathrm{H}$ mice exhibited significantly higher HDL-cholesterol levels $(\sim 90 \mathrm{mg} / \mathrm{dl})$ than B6 mice $(\sim 60 \mathrm{mg} / \mathrm{dl})$, and when challenged with the atherogenic diet, HDL-cholesterol levels in $\mathrm{C} 3 \mathrm{H}$ mice were unchanged whereas HDL-cholesterol levels in B6 mice decreased $\sim 50 \%$. The decrease in HDL-cholesterol in B6

Table I. Plasma Lipoprotein Levels in Parental Strains C57BL/6J and $\mathrm{C} 3 \mathrm{H} / \mathrm{HeJ}$

\begin{tabular}{lcccc}
\hline & \multicolumn{2}{c}{ Chow diet } & \multicolumn{2}{c}{ Atherogenic diet } \\
\hline & C57BL/6J & C3H/HeJ & C57BL/6J & C3H/HeJ \\
Total cholesterol & $83 \pm 14$ & $105 \pm 7$ & $163 \pm 34$ & $173 \pm 27$ \\
HDL cholesterol & $60 \pm 8^{* \ddagger}$ & $93 \pm 4^{*}$ & $34 \pm 11^{* \ddagger}$ & $94 \pm 6^{*}$ \\
LDL/VLDL cholesterol & $19 \pm 8$ & $15 \pm 9$ & $144 \pm 17^{*}$ & $89 \pm 24^{*}$
\end{tabular}

Values are expressed as $\mathrm{mg} / \mathrm{dl}$ of plasma, mean \pm SEM from three female mice in each group, on a normal chow diet and after 5 wk on an atherogenic diet. Significance is indicated for differences between strains on a particular diet $\left({ }^{*} P<0.01\right)$ and for same strain on different diets $\left({ }^{\ddagger} P<0.005\right)$. 
mice in response to the diet occurred within a 2- to 3-wk period (6; data not shown).

The distribution of plasma lipoprotein levels among female $(\mathrm{B} 6 \times \mathrm{C} 3 \mathrm{H}) \mathrm{F} 2$ intercross mice fed a chow $(75$ animals $)$ or an atherogenic diet for $8 \mathrm{wk}$ (185 animals) is shown in Fig. 2. Because gender has a significant influence on lipoprotein levels in mice, this study was limited to females to simplify the analyses. The wide range of lipoprotein levels among the F2 animals reflects the segregation of multiple genetic factors contributing to HDL and LDL/VLDL metabolism. The inheritance patterns were multifactorial, as there was no evidence of distinct groups of lipoprotein levels among the F2 progeny. The HDLcholesterol levels on both the chow and atherogenic diets in the F2 mice ranged largely between the parental values (Fig. 2 ). This suggests that the alleles carried by $\mathrm{C} 3 \mathrm{H}$ mice are primarily those that produce high HDL-cholesterol levels and the alleles carried by $\mathrm{B} 6$ mice are primarily those that produce low HDL-cholesterol levels. In contrast, the range of LDL/VLDLcholesterol levels in the F2 mice was significantly broader than the parental differences on both diets (Fig. 2). This suggests that $\mathrm{B} 6$ and $\mathrm{C} 3 \mathrm{H}$ mice exhibit multiple genetic differences contributing to LDL/VLDL levels, the combination of which leads to the two parental strains having relatively similar levels on both diets.

Construction of a complete linkage map for $(B 6 \times C 3 H) F 2$ progeny. We typed genetic markers in the $185 \mathrm{~F} 2$ mice at intervals of $\sim 10 \mathrm{cM}$ throughout the $1500 \mathrm{cM}$ mouse genome to test for linkage to plasma lipoprotein levels. Highly polymorphic simple sequence repeat markers were tested for polymorphisms between parental strains, and informative markers were used to type 185 F2 progeny. Altogether, over 134 microsatellite markers spanning all 19 autosomes and the X chromosome were typed. The data were analyzed using the Map Manager $(13,14)$ program and distances between the markers were calculated as a function of the recombinant fraction based on a model of crossover interference by Kosambi (19). The resulting linkage map is shown in Fig. 3. Due to the failure in some instances to identify polymorphic markers, gaps in the linkage
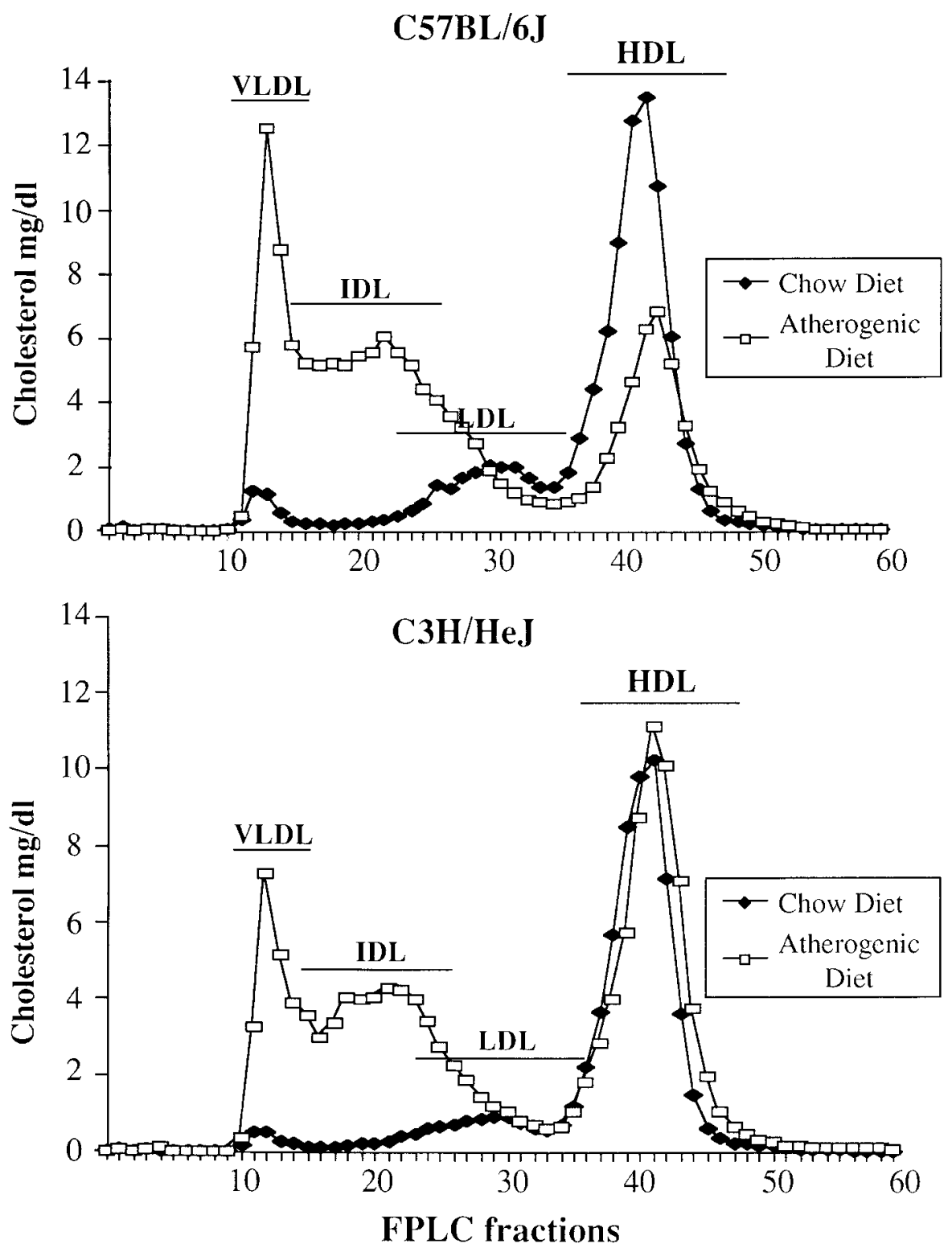

Figure 1. Plasma lipoprotein profiles in $\mathrm{B} 6$ and $\mathrm{C} 3 \mathrm{H}$ mice fed either chow or atherogenic diets. Pooled plasmas $(n=3)$ from female $\mathrm{B} 6$ and $\mathrm{C} 3 \mathrm{H}$ mice fed either chow or atherogenic diets were fractionated by fast performance liquid chromatography using 2 superose 6 columns in series. Fractions were then assayed for cholesterol in duplicate. All values are expressed in $\mathrm{mg} / \mathrm{dl}$ of plasma. The approximate positions of elution of VLDL, IDL, LDL, and HDL are indicated by bars. 

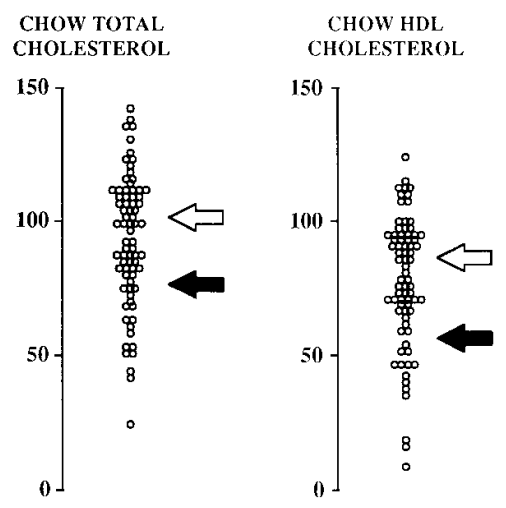

ATHEROGENIC DIET TOTAL CHOLESTEROL

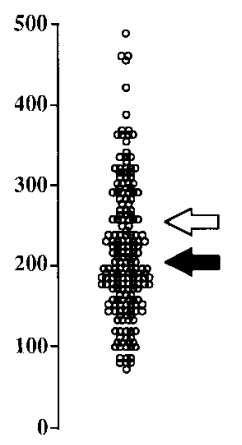

ATHEROGENIC DIET HDL CHOLESTEROL

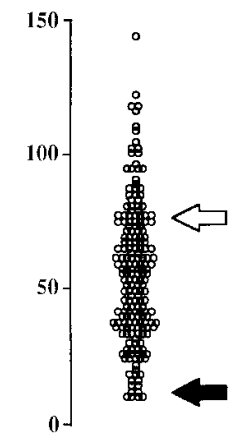

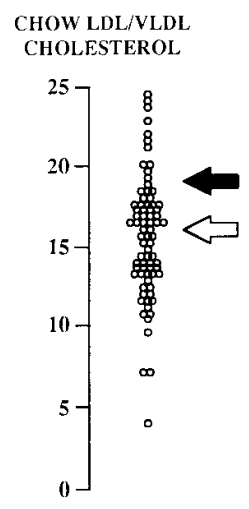

ATHEROGENIC DIET LDL/VLDL CHOLESTEROL

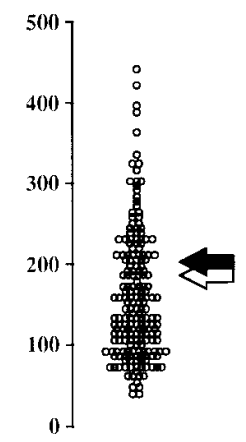

Figure 2. Distribution of plasma lipid levels among the F2 animals on the chow and atherogenic diets. All values are expressed as $\mathrm{mg} / \mathrm{dl}$. The scales differ between traits in order to illustrate their ranges in the F2 animals. The levels of LDL/VLDL-cholesterol were calculated by subtraction of HDL-cholesterol from total cholesterol. The open and filled arrows indicate the means observed in the parental strains $\mathrm{C} 3 \mathrm{H}$ and $\mathrm{B} 6$, respectively.

map greater than $20 \mathrm{cM}$ are present in a small number of chromosomal regions.

Identification of loci contributing to lipoprotein levels. We searched for genetic loci underlying the lipoprotein traits measured for the F2 mice by statistical analysis using the MAPMAKER/QTL program (15). The strength of association between genotypes at each locus and the phenotypes under investigation was expressed as a lod score, that is, the $\log _{10}$ of the odds ratio, a measure of the significance of the linkage results. The odds ratio is the ratio of the likelihood that the data can be explained by linkage (between a particular marker and the trait of interest) to the likelihood of the data given no linkage. Historically, a lod score of 3 (equal to an odds ratio of 1000:1) has been accepted as strong evidence of linkage, although more precise thresholds for significant linkage have been estimated using simulation studies. The thresholds are also influenced by the type of genetic cross, the number of traits analyzed, the number of markers tested, assumptions about the degrees of freedom, and distribution of the data (20). Permutation analysis was used to define appropriate thresholds for the primary traits of interest in this study. Table II shows all suggestive and significant linkages observed in this study with a lod score exceeding 2.5. Due to an error, lipoprotein levels on the chow diet were determined in only about half $(n=75)$ of the F2 progeny. This reduced the power for identi- fication of QTLs for lipoprotein levels on the chow diet as well as for changes in lipoprotein levels in response to the diet.

A locus on distal chromosome 1 containing the apoAII gene is a major determinant of HDL-cholesterol levels on both chow and atherogenic diets, but it does not determine the strain specific decrease in HDL-cholesterol in response to the atherogenic diet. The variation in total cholesterol and in HDL cholesterol on the chow diet was determined primarily by a locus on distal chromosome 1, the nearest marker being D1Mit36 (Table II; Fig. 4). The locus has a very significant lod score of 10.9 for HDL-cholesterol on the chow diet (Fig. $4 A$ ). Thus, F2 mice with the homozygous B6 genotype (BB) at D1Mit36 had HDL cholesterol levels of $48 \mathrm{mg} / \mathrm{dl}$, mice with the homozygous $\mathrm{C} 3 \mathrm{H}$ genotype $(\mathrm{HH})$ had HDL cholesterol levels of $96 \mathrm{mg} / \mathrm{dl}$, and mice which were heterozygous $(\mathrm{BH})$ had HDL cholesterol levels of $79 \mathrm{mg} / \mathrm{dl}$ (Fig. $4 \mathrm{~B}$ ). This region corresponds to the location of the structural gene for apolipoprotein AII (Apoa2), which has been shown previously to be a determinant of HDL cholesterol levels $(21,22)$.

When the F2 mice were challenged with the atherogenic diet for $8 \mathrm{wk}$, the distal chromosome 1 locus was still a major determinant of HDL cholesterol levels, having a lod score of 15.2 for HDL-cholesterol on the atherogenic diet (Fig. $4 A$ ). As with the chow diet, F2 animals with the BB genotype at D1Mit36 had the lowest levels of HDL cholesterol $(33 \mathrm{mg} / \mathrm{dl})$, animals with the $\mathrm{HH}$ genotype had the highest levels of HDL cholesterol $(72 \mathrm{mg} / \mathrm{dl})$ and heterozygous $(\mathrm{BH})$ animals were intermediate in HDL cholesterol (58 mg/dl) (Fig. $4 B$ ).

The net effect of the distal chromosome 1 locus on HDLcholesterol levels was remarkably similar between the chow and atherogenic diets. Thus, on the chow diet each $\mathrm{C} 3 \mathrm{H}$ allele at the locus (as compared to a B6 allele) resulted in an increase of HDL cholesterol by about $24 \mathrm{mg} / \mathrm{dl}$ whereas on the atherogenic diet each allele resulted in an increase of $\sim 20 \mathrm{mg} / \mathrm{dl}$ (Fig. 4 B). We conclude that this distal chromosome 1 region does not explain the decrease in HDL cholesterol in B6 mice in response to the dietary challenge. Thus, the previous conclusion (1) that a major locus, designated Ath-1, controls the response of HDL and atherogenesis to a dietary challenge, appears to be incorrect.

Besides the Apoa2 gene locus, two additional loci with significant effects on total cholesterol levels and on HDL cholesterol on the chow diet were observed in this cross (Fig. 3 and Table II). The first resides near the marker D7Mit227 on chromosome 7 and the second resides near the marker D18Mit124 on chromosome 18 . The locus on chromosome 7 contains several candidate genes, including the apolipoprotein E (Apoe), hormone sensitive lipase (Lipe) and serum amyloid A (Saa) genes. The locus on chromosome 18 does not contain any obvious candidate genes (17).

Multiple loci mediating the decrease in HDL-cholesterol levels in response to the atherogenic diet. Several loci with effects on HDL-cholesterol on the atherogenic diet but not the chow diet were observed in this cross (Table II and Fig. 5). In each case, with the exception of the chromosome 4 locus (D4Mit111), the $\mathrm{B} 6$ allele, as compared with the $\mathrm{C} 3 \mathrm{H}$ allele, resulted in decreased HDL-cholesterol levels on the atherogenic diet. In contrast, there were no significant effects on the chow diet (Fig. 5). The loci had suggestive lod scores (2.5 to 3.4 ) as defined by the permutation analysis. Presumably, this is due to the fact that the inheritance of HDL-cholesterol levels is complex and because no one locus, other than D1Mit36, has a ma- 

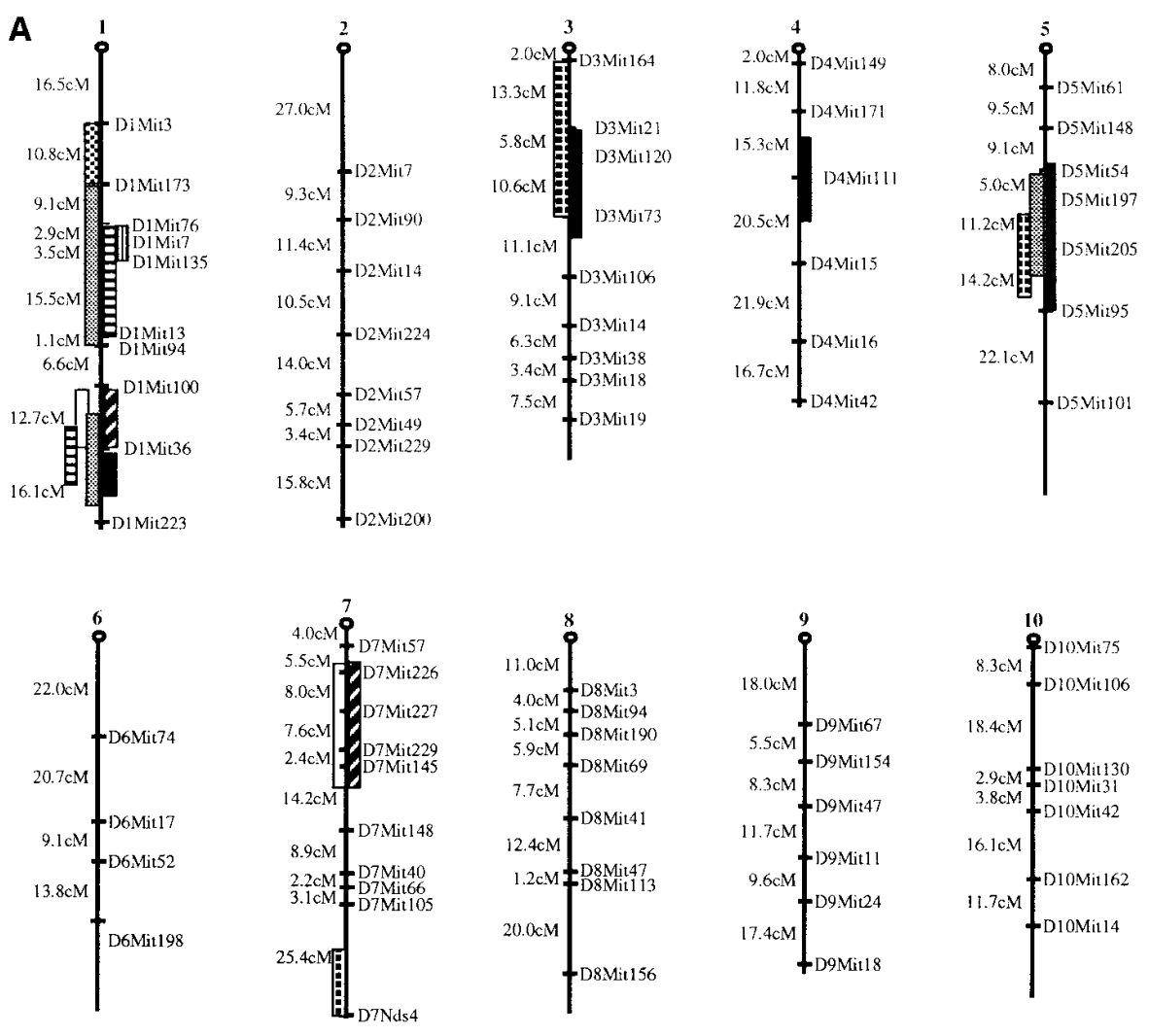

B
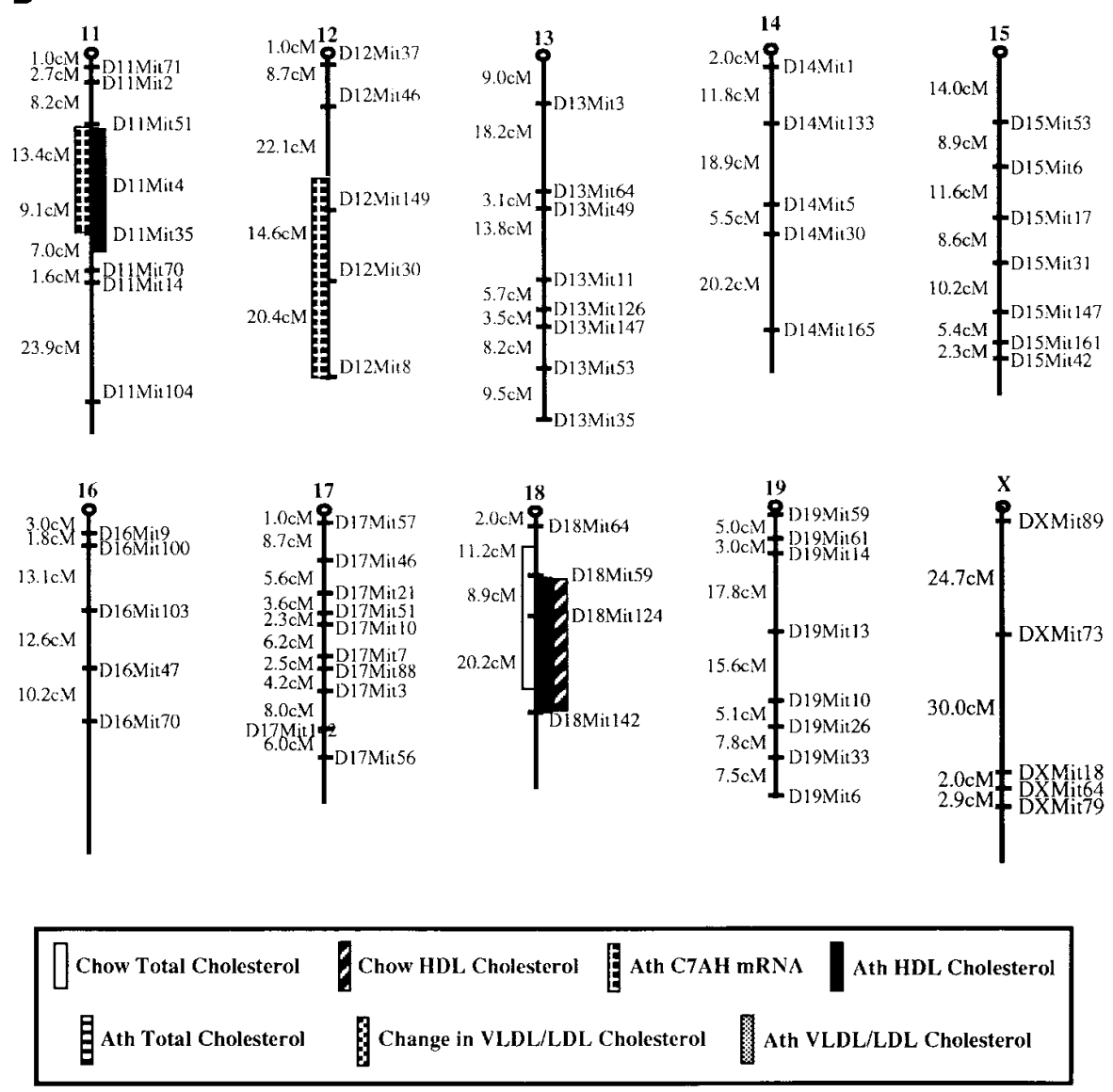

Figure 3. Linkage map of microsatellite markers in the $(\mathrm{B} 6 \times \mathrm{C} 3 \mathrm{H}) \mathrm{F} 2$ intercross. Genetic distances between the markers (indicated to the left of the chromosomes) are calculated as centiMorgans (cM) using the Kosambi function. Chromosomes were drawn to scale and their sizes as well as the distance of the most proximal marker to the centromere were from the Committee Report maps supplied by the Jackson Laboratories (Bar Harbor, ME) (27). The positions of QTLs for the traits specified in the boxed area are indicated on the map by rectangles spanning the $95 \%$ confidence interval. 


\begin{tabular}{|c|c|c|c|c|c|}
\hline Trait & Diet & Chromosome & Nearest marker & lod score* & $\begin{array}{l}\text { Variance } \\
\text { explained* }\end{array}$ \\
\hline \multirow[t]{5}{*}{ Total cholesterol } & Chow & 1 & D1Mit36 & 14.0 & $64 \%$ \\
\hline & "' & 7 & D7Mit227-D7Mit229 & 3.0 & $17 \%$ \\
\hline & " & 18 & D18Mit59-D18Mit124 & 4.4 & $28 \%$ \\
\hline & Ath & 1 & D1Mit135 & 5.7 & $15 \%$ \\
\hline & "' & 1 & D1Mit36 & 9.3 & $20 \%$ \\
\hline \multirow[t]{3}{*}{ VLDL/LDL cholesterol } & Ath & 1 & D1Mit135 & 3.0 & $8 \%$ \\
\hline & " & 1 & D1Mit36 & 3.8 & $9 \%$ \\
\hline & " & 5 & D5Mit205 & 2.6 & $7 \%$ \\
\hline \multirow[t]{9}{*}{ HDL cholesterol } & Chow & 1 & D1Mit36 & 10.9 & $60 \%$ \\
\hline & " & 7 & D7Mit227-D7Mit229 & 4.0 & $22 \%$ \\
\hline & $" \prime$ & 18 & D18Mit124-D18Mit142 & 3.5 & $31 \%$ \\
\hline & Ath & 1 & D1Mit36 & 15.2 & $35 \%$ \\
\hline & '" & 3 & D3Mit120 & 2.5 & $6 \%$ \\
\hline & " & 4 & D4Mit111 & 2.8 & $7 \%$ \\
\hline & " & 5 & D5Mit205 & 3.4 & $8 \%$ \\
\hline & " & 11 & D11Mit4 & 2.5 & $7 \%$ \\
\hline & $\prime \prime$ & 18 & D18Mit124-D18Mit142 & 3.0 & $9 \%$ \\
\hline \multirow[t]{5}{*}{ C7AH mRNA levels } & Ath & 3 & D3Mit120 & 5.8 & $14 \%$ \\
\hline & "' & 5 & D5Mit205 & 3.7 & $9 \%$ \\
\hline & " & 7 & $D 7 N d s 4$ & 2.9 & $7 \%$ \\
\hline & $\prime \prime$ & 11 & D11Mit4 & 4.4 & $13 \%$ \\
\hline & " & 12 & D12Mit8 & 3.9 & $10 \%$ \\
\hline $\begin{array}{l}\text { Change in VLDL/LDL } \\
\text { cholesterol }\end{array}$ & NA & 1 & D1Mit3-D1Mit173 & 5.0 & $35 \%$ \\
\hline
\end{tabular}

*Values were calculated using the MAPMAKER/QTL program. Ath denotes the atherogenic diet. The change in any trait is the difference between the chow diet value and the Ath diet value.

jor influence on HDL levels (Table II). As described below, the evidence for the loci is strengthened by studies of bile acid metabolism and $\mathrm{C} 7 \mathrm{AH}$ expression. Together, the estimated variance explained by the loci could account for the two- to threefold decrease in HDL cholesterol in B6 mice in response to the diet. Because chow values for HDL levels were available for only a fraction of the F2 progeny (see above), the power to detect linkage for the change in HDL-cholesterol in response to the diet has greatly diminished. Nevertheless, mice homozygous for the $\mathrm{C} 3 \mathrm{H}$ allele at the chromosome 11 locus (D11Mit4) had significantly less change in HDL-cholesterol than did mice heterozygous at the locus $(P=0.03)$, and mice homozygous for the $\mathrm{C} 3 \mathrm{H}$ allele at the chromosome 5 locus had a trend toward less change in HDL cholesterol than mice homozygous for the $\mathrm{B} 6$ allele $(P=0.12)$. In addition, the change in HDL-cholesterol in response to the diet was highly correlated with the levels of C7AH mRNA $(P=0.0002)$ (Table III). The Apoa2 locus (D1Mit36) showed no evidence of an association with the change in HDL-cholesterol in response to the diet.

Loci contributing to LDL/VLDL-cholesterol levels. Three loci contributing to LDL/VLDL-cholesterol levels were identified. The first locus resides on mouse chromosome 1, considerably proximal to Apoa2. The second locus is located on distal chromosome 1 corresponding to Apoa2. The third locus is in the central region of mouse chromosome 5 (Table II). The proximal chromosome 1 and the chromosome 5 loci do not contain any obvious candidate genes. The distal chromosome 1 locus likely results from variations in the expression of apoAII, since apoAII transgenic mice exhibit small but significant increases in LDL/VLDL-cholesterol levels (22). The locus on proximal mouse chromosome 1 was particularly striking (lod score $=5.0$ ) when the data were analyzed as the change in total plasma cholesterol or LDL/VLDL-cholesterol in response to the dietary challenge (Fig. 6, Table II). The presence of loci contributing to LDL/VLDL-cholesterol levels is consistent with the idea that $\mathrm{C} 3 \mathrm{H}$ and $\mathrm{B} 6$ mice exhibit genetic differences in LDL/VLDL metabolism despite the fact that they have similar levels of LDL/VLDL-cholesterol (Table I, Fig. 2). Fig. 7 shows the levels of LDL/VLDL-cholesterol in the F2 mice separated by genotypes at the three loci.

A genetic link between bile acid metabolism and HDL metabolism. To examine whether differences in the regulation of C7AH could underlie, in part, the genetic control of HDLcholesterol levels in response to the atherogenic diet, we examined the levels of $\mathrm{C} 7 \mathrm{AH}$ mRNA in livers of $\mathrm{B} 6$ and $\mathrm{C} 3 \mathrm{H}$ mice on both chow and atherogenic diets using an RNase protection assay (Fig. 8). On a chow diet, B6 mice exhibited somewhat higher levels of mRNA than $\mathrm{C} 3 \mathrm{H}$ mice, but after a challenge with the atherogenic diet containing cholic acid the responses were strikingly different. B6 mice showed a large decrease, about fivefold, in mRNA levels, whereas $\mathrm{C} 3 \mathrm{H}$ mice showed a small but significant increase in mRNA levels. Thus, on the atherogenic diet, the expression of $\mathrm{C} 7 \mathrm{AH}$ between the two strains differed more than fourfold. This difference in C7AH mRNA response has been observed in several indepen- 
A

\section{Chromosome 1}
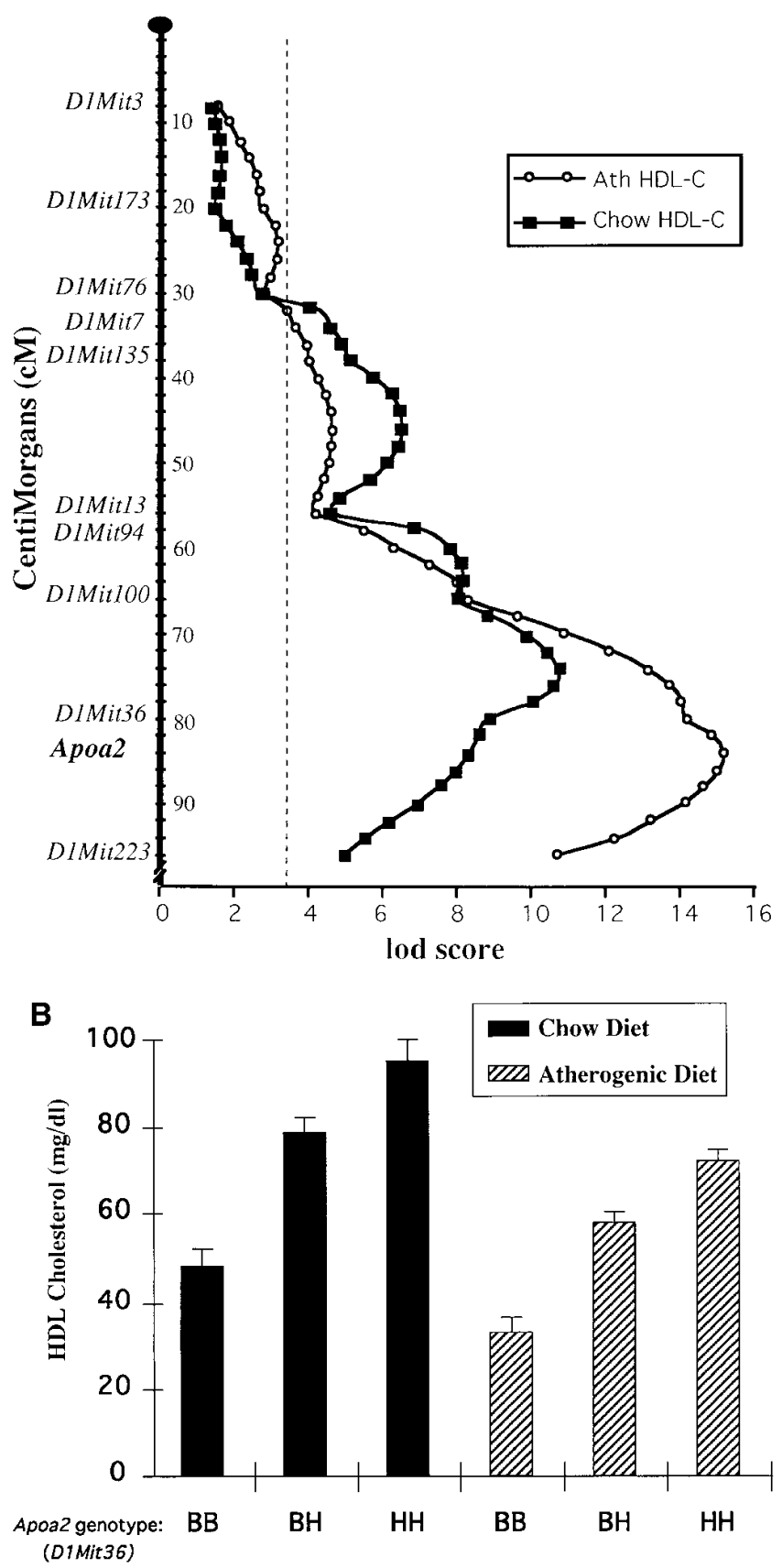

Figure 4. The Apoa 2 locus on distal chromosome 1 determines HDLcholesterol levels on both chow and atherogenic (Ath) diets. $(A)$ QTL plot of chromosome 1 with the $\mathrm{Y}$ axis indicating distance along chromosome 1 at $2 \mathrm{cM}$ intervals and the $x$-axis giving the lod scores for each $2 \mathrm{cM}$ increment. The significance threshold of $P=0.05$ for this data is indicated by a dashed line (lod score of 3.4) and was determined by permutation analysis as described in Methods. (B) Histogram which displays the mean \pm SEM of all F2 animals with a particular genotype, using the marker D1Mit36 at the Apoa2 locus. BB designates the animals homozygous for the $\mathrm{B} 6$ allele at the Apoa 2 locus, $B H$ designates the animals heterozygous at this locus, and $H H$ designates the animals homozygous for the $\mathrm{C} 3 \mathrm{H}$ allele at this same locus. dent experiments, and results using RNase protection and Northern blotting followed by densitometry were very similar (data not shown).

Coincident genetic loci controlling $C 7 A H$ expression and HDL levels. The distribution of C7AH mRNA levels among the $\mathrm{F} 2$ progeny are shown in Fig. 9. F1 animals exhibited intermediate C7AH mRNA levels, indicating that the trait is inherited in a codominant fashion. Interestingly, a correlation of HDL-cholesterol levels from mice on the atherogenic diet was seen with C7AH mRNA levels $(r=0.51 ; P<0.004)$ (Table III). This suggests that these two traits exhibit coordinate regulation. On the other hand, no significant correlation was observed between LDL/VLDL cholesterol levels and C7AH mRNA levels.

Hepatic C7AH mRNA levels among F2 mice were subjected to QTL analysis using the MAPMAKER/QTL program. A total of five significant or suggestive loci were identified, on chromosomes 3, 5, 7, 11, and 12 (Table II). None of these loci corresponded to the location of the $\mathrm{C} 7 \mathrm{AH}$ structural gene on chromosome 4 (see below), indicating that the loci were acting in trans to influence either production or turnover of $\mathrm{C} 7 \mathrm{AH}$ mRNA. These loci contain several candidate genes. For example, the chromosome 5 and chromosome 11 loci encode the transcription factors HNF-1 (Tcf1) and vHNF-1 (Tcf2), respectively, both of which recognize cis-elements located in the promoter region of the $\mathrm{C} 7 \mathrm{AH}$ gene (8). Also, members of a family of $3 \beta$-hydroxysteroid dehydrogenase genes, thought to be involved in the metabolism of 7 alpha hydroxycholesterol, reside near the QTLs on chromosomes 3, 5, and 7 (23, 24). The metabolites of 7 alpha hydroxycholesterol could indirectly influence the expression of C7AH since 7 alpha hydroxycholesterol can be metabolized to bile acids which are known to act negatively on C7AH expression. It is also noteworthy that evidence exists for a "bile acid receptor" which binds to a cis-acting element, $7 \alpha \mathrm{TRE}$, in the C7AH promoter (25). Conceivably, the HDL loci could contain genes responsive to the bile acid receptor or regulating receptor expression.

Significantly, three of the five loci for C7AH mRNA levels, on chromosomes 3,5 , and 11 , were coincident with the loci for

Table III. Strength of Association between Plasma Lipoprotein Cholesterol and C7AH mRNA Levels in (C57BL/6J $\times$ C3H/HeJ) F2 Animals

\begin{tabular}{lccc}
\hline & $\begin{array}{c}\text { Total } \\
\text { cholesterol }\end{array}$ & $\begin{array}{c}\text { HDL- } \\
\text { cholesterol }\end{array}$ & $\begin{array}{c}\text { LDL/VLDL- } \\
\text { cholesterol }\end{array}$ \\
\hline Total cholesterol & & $0.755^{*}$ & $0.675^{*}$ \\
HDL cholesterol & $0.352^{*}$ & & $0.470^{*}$ \\
LDL/VDL cholesterol & $0.956^{*}$ & 0.061 & \\
C7AH mRNA levels & 0.056 & $0.506^{*}$ & 0.235 \\
\hline
\end{tabular}

Strength of association expressed as Spearman's rho between quantitative measures of plasma lipoprotein and $\mathrm{C} 7 \mathrm{AH}$ mRNA levels in 185 $(\mathrm{C} 57 \mathrm{BL} / 6 \mathrm{~J} \times \mathrm{C} 3 \mathrm{H} / \mathrm{HeJ}) \mathrm{F} 2$ mice. Values to the top right of the diagonal are Spearman rank correlation coefficients (rho) for phenotypes measured on a chow diet, and values to the bottom left are correlation coefficients for phenotypes after $8 \mathrm{wk}$ on an atherogenic diet. Using the formula for the adjusted level of significance $=0.1 /(2 \times$ number of comparisons) with a total of 12 comparisons, the required $P$ value for significance was calculated to be $\sim 0.004$. Correlations significant to this level are indicated by an asterisk. 
A.
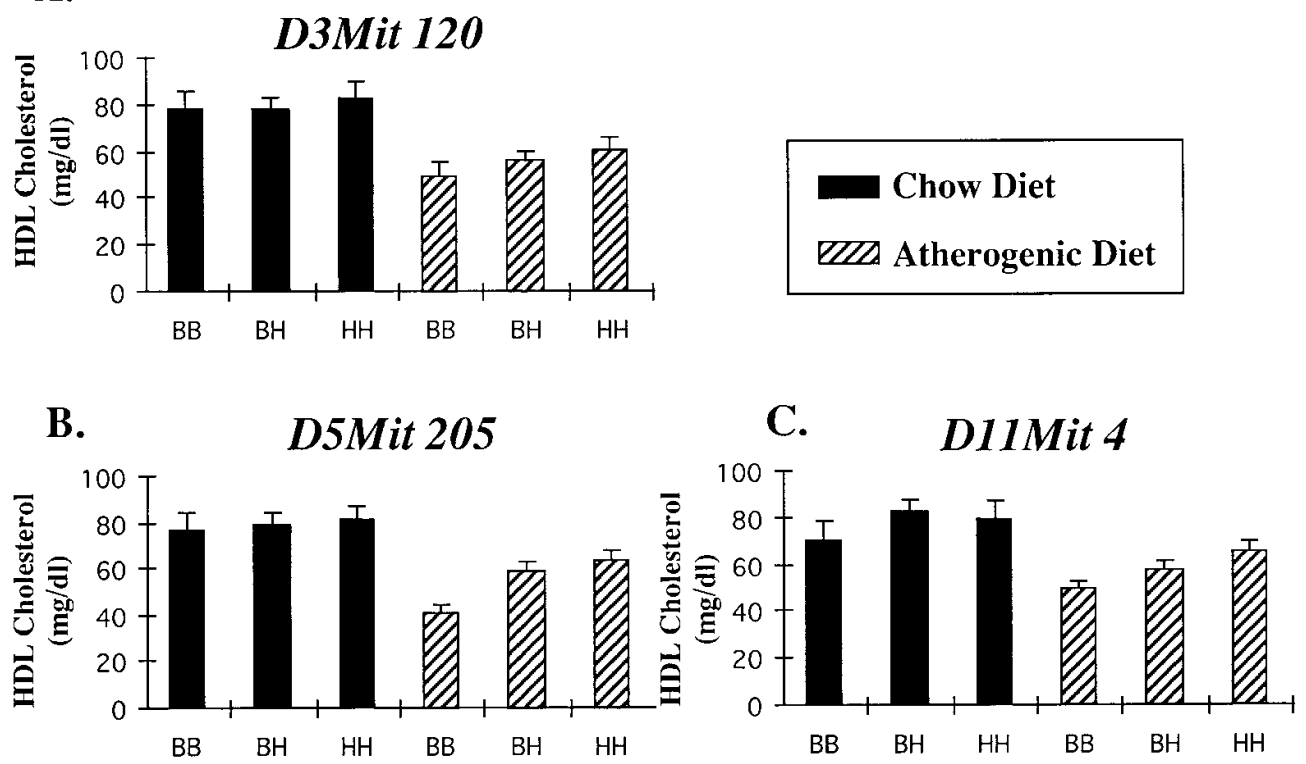

Figure 5. The HDL-cholesterol QTLs on chromosomes 3, 5, and 11 determine cholesterol levels on the atherogenic but not chow diets. Values are displayed as the mean \pm SEM of $\mathrm{F} 2$ mice with a particular genotype at the designated loci. Genotypic combinations are designated as in Fig. 4 with $B$ representing the $\mathrm{B} 6$ allele and $H$ representing the $\mathrm{C} 3 \mathrm{H}$ allele.

HDL-cholesterol levels on an atherogenic diet (Fig. 10). This suggests that there is a genetic link between HDL-cholesterol levels and bile acid metabolism. Both the HDL-cholesterol loci and the $\mathrm{C} 7 \mathrm{AH}$ loci individually covered only a few percent

\section{Chromosome 1}

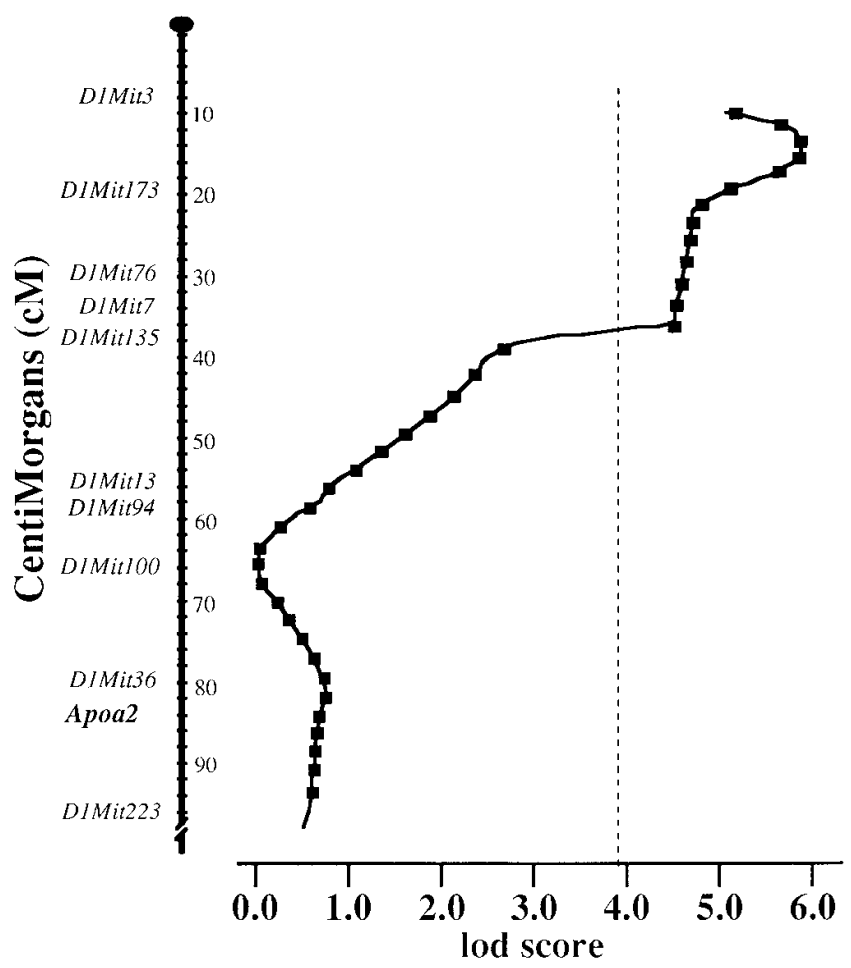

Figure 6. A QTL for the change in LDL/VLDL cholesterol on proximal mouse chromosome 1 . The trait was quantitated by subtracting the LDL/VLDL cholesterol value on the chow diet from the LDL/ VLDL cholesterol value on the atherogenic diet for each F2 animal. The significance threshold of $P=0.05$ for this data is indicated by a dashed line (indicating a lod score of 3.8) and was determined by permutation analysis as described in Methods. or less of the mouse genome. Therefore, the likelihood that three of the six HDL-cholesterol loci and three of the five $\mathrm{C} 7 \mathrm{AH}$ loci would coincide by chance is remote. It is noteworthy that the three coincident loci for HDL-cholesterol were observed only on the atherogenic diet; this is consistent with the observation that $\mathrm{C} 7 \mathrm{AH}$ expression differs between $\mathrm{B} 6$ and $\mathrm{C} 3 \mathrm{H}$ mice much more dramatically on the atherogenic diet than on the chow diet (Fig. 8). There was also overlap between a locus on chromosome 5 controlling LDL/VLDL cholesterol on the atherogenic diet and the chromosome 5 locus controlling C7AH expression (Table II). Thus, these findings support the concept that $\mathrm{C} 7 \mathrm{AH}$ expression is in some manner linked to plasma lipoprotein levels, particularly HDL-cholesterol levels, in the mouse.

The coincidental mapping of QTLs for C7AH mRNA levels and HDL-cholesterol levels on an atherogenic diet can be attributed to one of three possibilities: first, HDL-cholesterol levels influence $\mathrm{C} 7 \mathrm{AH}$ expression; second, $\mathrm{C} 7 \mathrm{AH}$ influences HDL-cholesterol levels; and third, common genes regulate both. The first possibility can be excluded because this study shows that the most significant HDL-cholesterol QTL (lod of

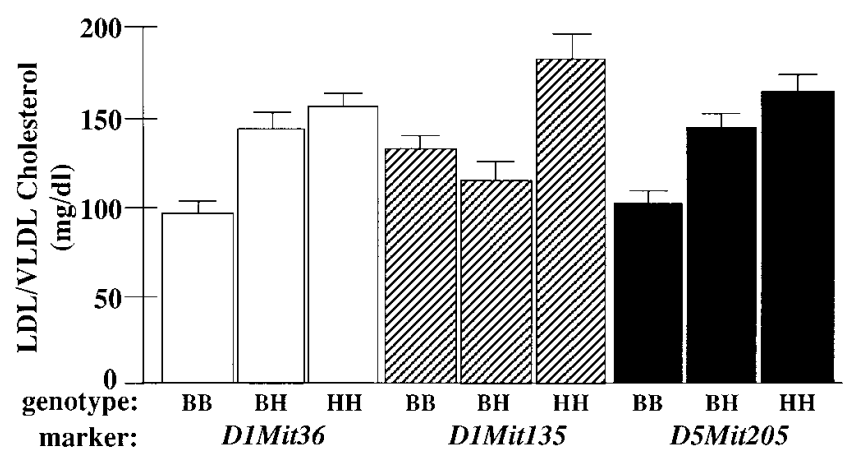

Figure 7. The LDL/VLDL cholesterol levels of F2 mice on the atherogenic diet subdivided by genotypes at the chromosome 1 and 5 QTLs. Values are the means of each group in $\mathrm{mg} / \mathrm{dl} \pm$ SEM. B6 alleles are indicated by $B$ and $\mathrm{C} 3 \mathrm{H}$ alleles by $H$. 


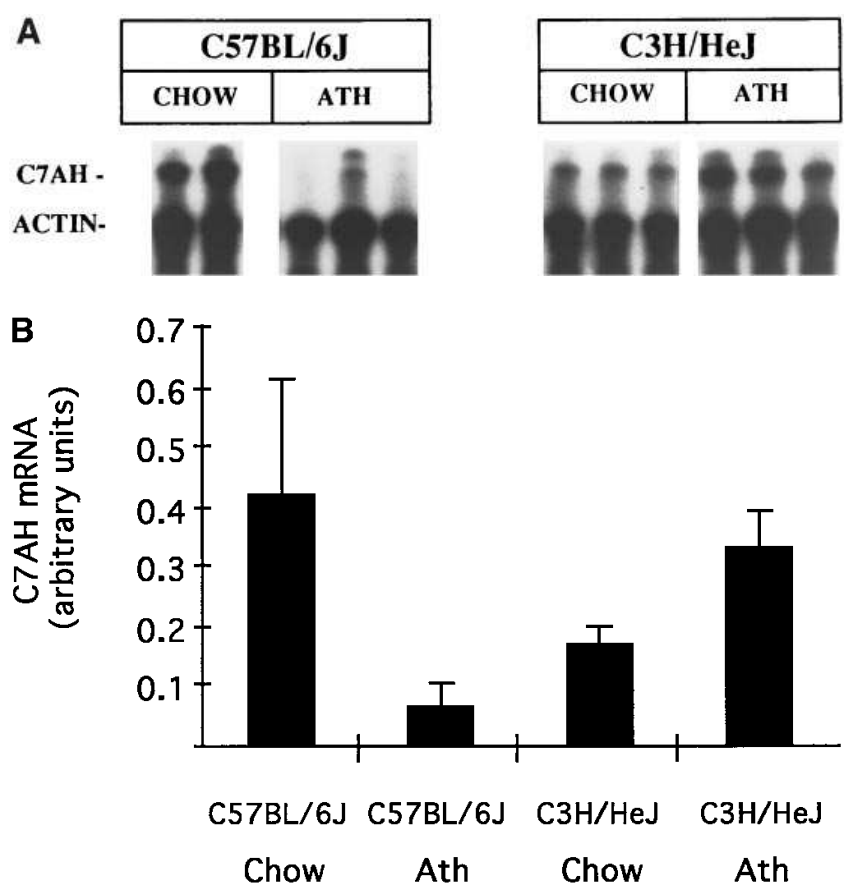

Figure 8. Hepatic C7AH mRNA levels in the parental inbred strains $\mathrm{B} 6$ and $\mathrm{C} 3 \mathrm{H}$ on the chow and atherogenic diets. $(A)$ autoradiogram of products from a ribonuclease protection assay for C7AH mRNA in livers of $\mathrm{B} 6$ and $\mathrm{C} 3 \mathrm{H}$ mice maintained on chow or atherogenic (Ath) diets. Female $\mathrm{B} 6$ and $\mathrm{C} 3 \mathrm{H}$ mice were maintained on the chow diet or atherogenic diet (for $5 \mathrm{wk}$ ), and total liver RNA was isolated. The RNA ( $20 \mu \mathrm{g}$ per sample) was then subjected to a ribonuclease protection assay for $\mathrm{C} 7 \mathrm{AH}$ and actin (as an internal standard) and the labeled products were separated by polyacrylamide gel electrophoresis and subjected to autoradiography (see Methods). Each lane represents a separate animal. The protected fragments are indicated; the actin bands are overexposed to allow visualization of the $\mathrm{C} 7 \mathrm{AH}$ in the samples. (B) Histogram reflecting the quantitation of C7AH mRNA normalized to actin mRNA. Bands in the autoradiogram were quantitated by densitometric scanning and the signal for $\mathrm{C} 7 \mathrm{AH}$ was normalized to that for actin. Measurements were taken from three animals in each strain and diet group and a mean \pm SEM was calculated.

15.2), on chromosome 1 , has no influence on $\mathrm{C} 7 \mathrm{AH}$ mRNA levels. No significant or even suggestive lod scores occur in this region for C7AH mRNA levels. Additionally, apoA-I transgenic mice, which exhibit high levels of plasma HDL, showed no change in C7AH mRNA levels when compared to nontransgenic littermates (data not shown).

Trans-genetic regulation of $\mathrm{C} 7 \mathrm{AH}$ in response to a dietary challenge. The genetic factors contributing to differences in the expression of $\mathrm{C} 7 \mathrm{AH}$ could be due to genetic differences in the structural gene or to genetic differences influencing $\mathrm{C} 7 \mathrm{AH}$ expression in trans, such as transcription factors. To test this, we determined the chromosomal location of the mouse $\mathrm{C} 7 \mathrm{AH}$ gene by linkage analysis. A restriction fragment length variant (RFLV) between the B6 and the Mus spretus strains was identified. Southern blots of HindIII digested genomic DNA from B6 mice produced a unique $2.9 \mathrm{~kb}$ fragment whereas DNA from Mus spretus mice produced a unique $6.6 \mathrm{~kb}$ fragment. A total of 67 progeny from a $(\mathrm{B} 6 \times$ Mus spretus $) \mathrm{F} 1 \mathrm{X}$ B6 backcross were typed for the RFLV and its segregation pattern was compared with over 300 previously typed markers in this cross.

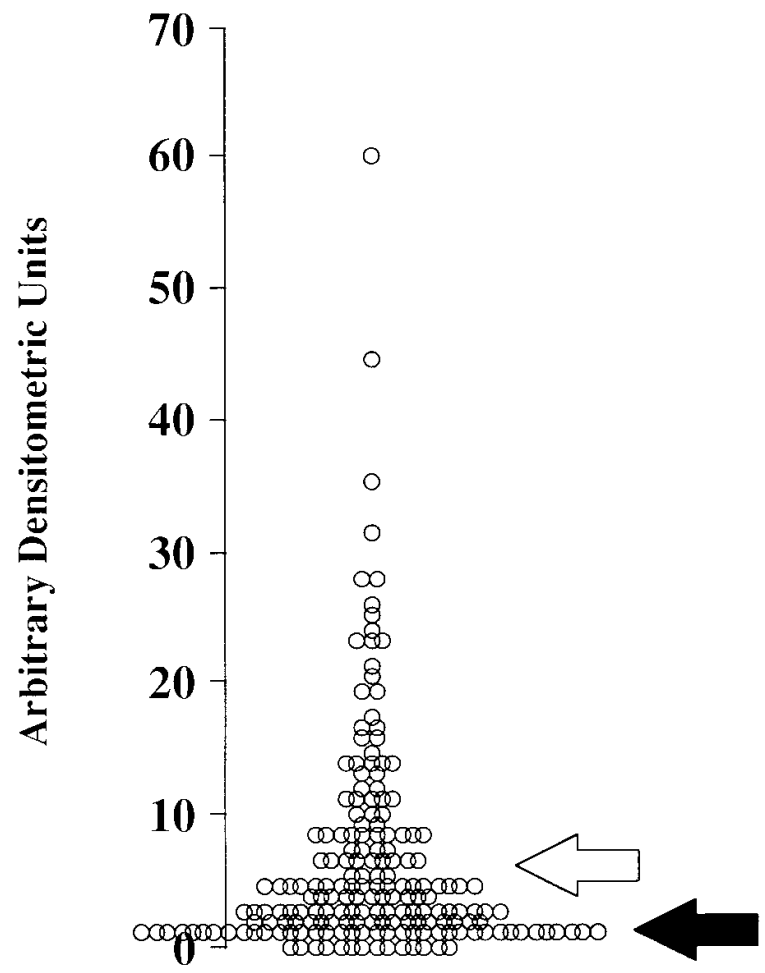

Figure 9. The distribution of C7AH mRNA levels in the F2 mice. Values were normalized as described in Methods and are given as arbitrary units. Signals were detected using a PhosphorImager (Molecular Dynamics) and were quantitated by the integration of a profile plot of the band signal. The open and filled arrows indicate the means observed in the parental strains $\mathrm{C} 3 \mathrm{H}$ and $\mathrm{B} 6$, respectively.

Linkage was analyzed using the MapManager program (13, 14). The structural gene for $\mathrm{C} 7 \mathrm{AH}$, designated $C y p 7$, was found to reside $6.1 \pm 2.9 \mathrm{cM}$ proximal to the marker D4Mit19 on chromosome 4 (Fig. 11). This region is syntenic with human chromosome 8q11-q11.2 which contains the human $\mathrm{C} 7 \mathrm{AH}$ gene, CYP7 $(26,27)$.

Loci controlling $C 7 A H$ expression and HDL-cholesterol levels influence the formation of gallstones. When maintained on an atherogenic diet, strain B6 mice developed gallstones whereas strain $\mathrm{C} 3 \mathrm{H}$ mice were relatively resistant $(5,28)$. We examined gallstone formation among the $(\mathrm{B} 6 \times \mathrm{C} 3 \mathrm{H}) \mathrm{F} 2$ mice using either gallstone mass (measured in $\mathrm{mg}$ of cholesterol) or a semiquantitative assay for gallstone size. In the latter assay, stone formation was scored by giving a numerical value for five visibly definable stages in gallstone formation. Two of the loci, on chromosomes 5 and 11, exhibited significant associations with gallstones. The chromosome 5 locus showed the highest significance with gallstone mass while the chromosome 11 locus showed the highest significance with gallstone formation (Fig. 12). In both cases, the $\mathrm{C} 3 \mathrm{H}$ alleles were associated with a reduced presence of gallstones. These results suggest that common genetic factors contribute to the genetic-dietary interactions involved in $\mathrm{C} 7 \mathrm{AH}$ mRNA levels, HDL-cholesterol levels and gallstone formation. This observation is further substantiated by the fact that gallstone mass showed a negative association with C7AH mRNA levels $(r=-0.252$, $P=0.0005)$ and with HDL-cholesterol levels $(r=-0.235, P=$ $0.001)$, on the atherogenic diet, in the $(\mathrm{B} 6 \times \mathrm{C} 3 \mathrm{H}) \mathrm{F} 2$ mice. 
A

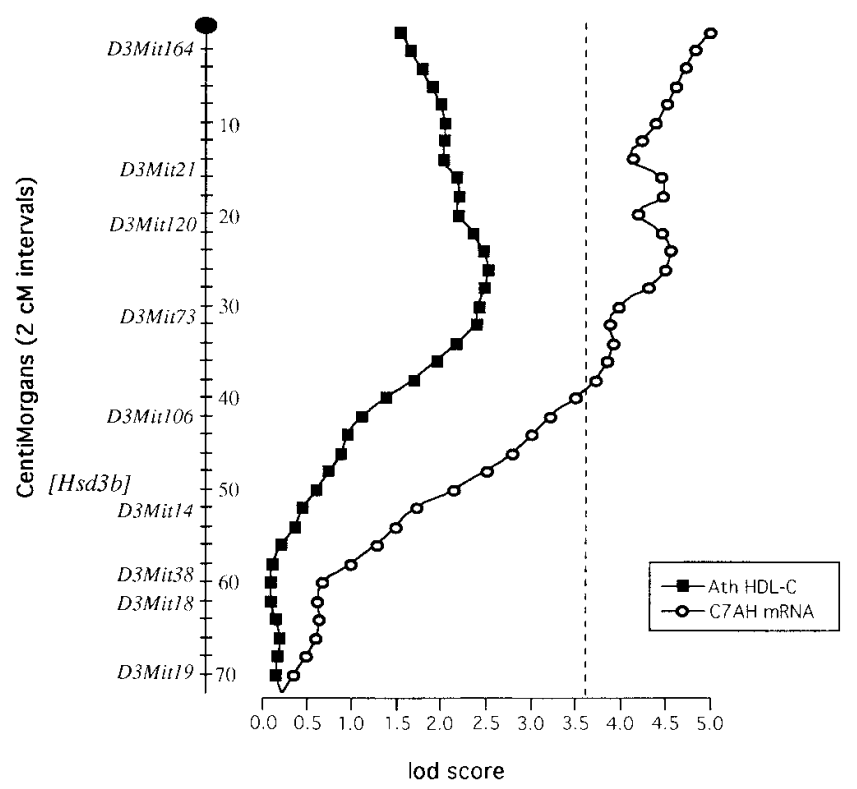

C

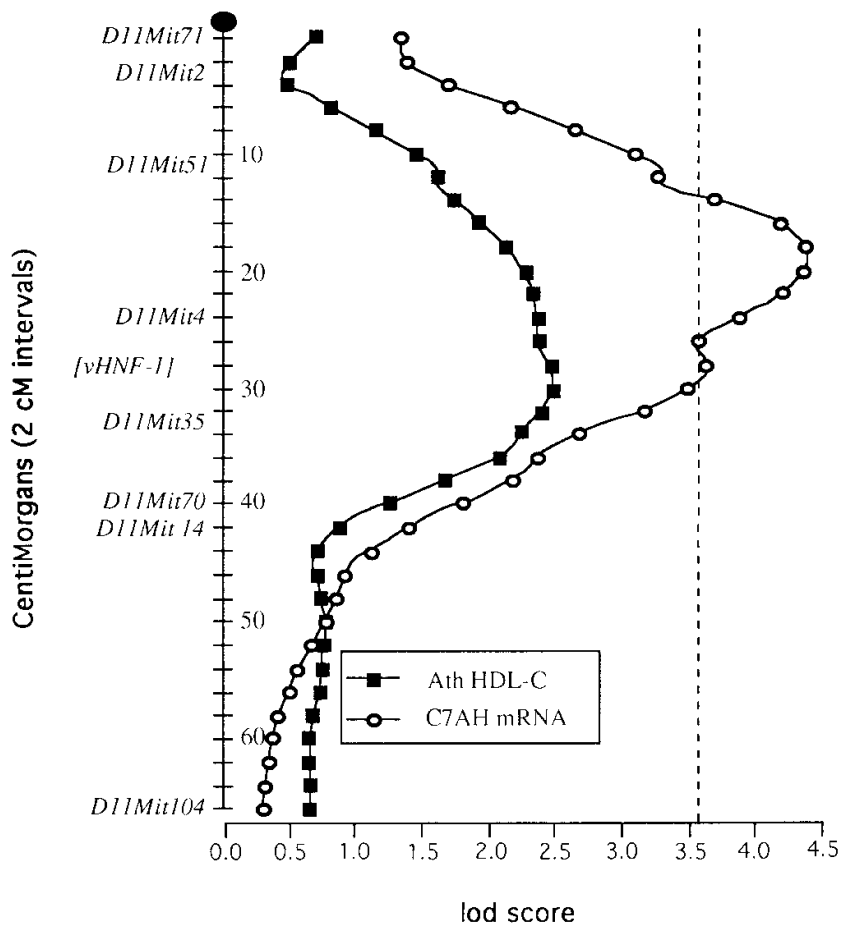

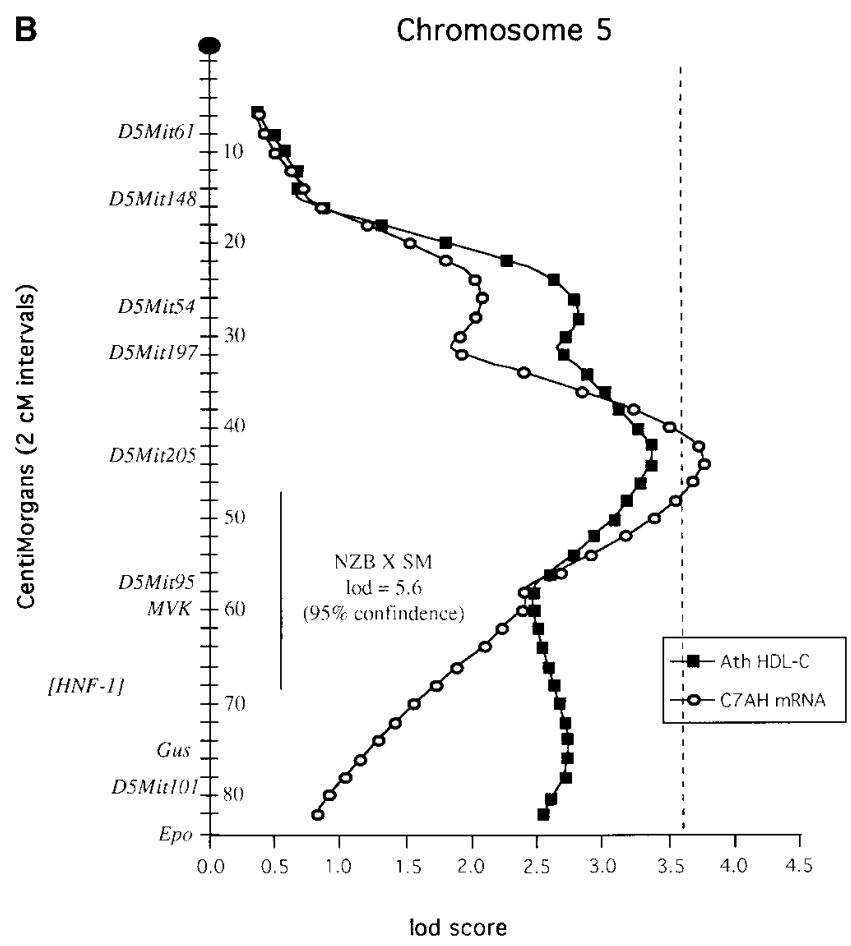

lod score

Figure 10. Loci on chromosome $3(A)$, chromosome $5(B)$, and chromosome $11(C)$ which contribute to plasma HDL-cholesterol and $\mathrm{C} 7 \mathrm{AH}$ mRNA levels on an atherogenic diet. The $\mathrm{X}$-axis gives the lod score values. The significance threshold of $P=0.05$ for these data is indicated by a dashed line (indicating a lod score of 3.6) and was determined for C7AH mRNA levels by permutation analysis as described in the Methods. The $\mathrm{Y}$-axis represents the chromosomes with ticks placed at every $2 \mathrm{cM}$ where a lod score has been calculated by the MAPMAKER/QTL program. The positions of markers and candidate genes are indicated along the chromosomes. Also included on $B$ is the location of a previously published QTL for HDL-cholesterol on the atherogenic diet with a cross between strains NZB $\times$ SM (7).

\section{Discussion}

Our results show that the genetic control of HDL-cholesterol levels between strains $\mathrm{B} 6$ and $\mathrm{C} 3 \mathrm{H}$ is more complex than suggested by previous studies of RI strains. In agreement with previous results, a locus on distal chromosome 1 containing the apoAII gene was found to be important in the control of HDL

metabolism $(1,18,21,29)$. However, our results show that this locus does not contribute to the decrease in HDL cholesterol in B6 mice challenged with the atherogenic diet. That is, the locus contributed equally to the HDL levels on both the chow and atherogenic diets (Fig. 4). Rather, several distinct loci, located on separate chromosomes, were found to contribute to the dietary control of HDL cholesterol; thus, these loci were 


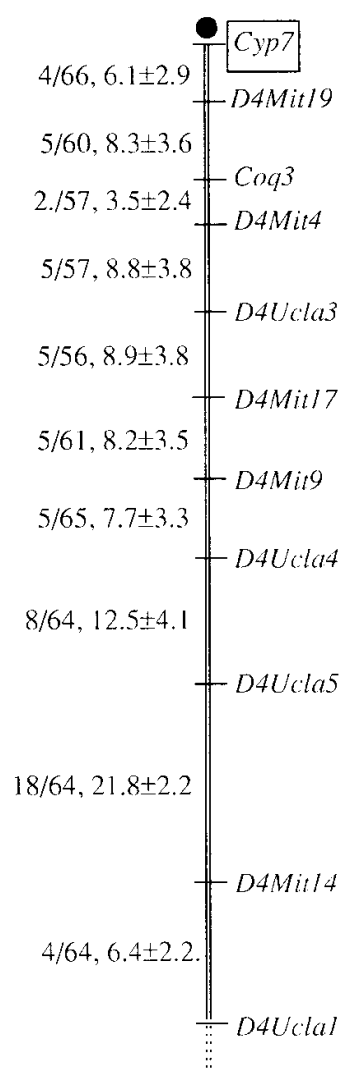

Figure 11. Mapping of the mouse C7AH gene, Cyp 7, to chromosome 4 in an interspecific backcross $[(\mathrm{B} 6 \times$ Mus spretus) $\mathrm{F} 1 \times \mathrm{B} 6]$. The ratios of the number of recombinants to the total number of informative mice and the recombination frequencies \pm SEM (in $\mathrm{cM}$ ), for each pair of loci, are indicated to the left of the chromosome. The markers to the right have been mapped as previously reported (17).

restricted to the atherogenic diet in influencing the HDL-cholesterol levels (Fig. 5). At least three of these loci were associated with differences in the expression of $\mathrm{C} 7 \mathrm{AH}$, the rate limiting enzyme in the synthesis of bile acids. Below, we discuss these points in turn.

The QTL for HDL-cholesterol levels on distal chromosome 1 is due to variations of the apoAII gene. We have previously shown that differences in apoAII expression occur between strains $\mathrm{C} 3 \mathrm{H}$ and $\mathrm{B} 6$, with strain $\mathrm{C} 3 \mathrm{H}$ mice expressing about twice as much plasma apoAII as B6 mice (about 31 and $16 \mathrm{mg} /$ $\mathrm{dl}$, respectively) (21). Moreover, in a set of recombinant inbred strains derived from $\mathrm{C} 3 \mathrm{H}$ and $\mathrm{B} 6$ mice, HDL cholesterol levels

segregated with the Apoa2 locus on chromosome 1 (6), consistent with our present results. Previous genetic (7) and transgenic (30) studies are consistent with the concept that the chromosome 1 QTL is in fact due to variations in the expression of apoAII. In particular, transgenic mice over expressing mouse apoAII had elevated HDL cholesterol levels as compared to nontransgenic littermates and the HDL particles were somewhat larger (30).

HDL metabolism and atherosclerosis. From studies of RI strains derived from $\mathrm{B} 6$ and $\mathrm{C} 3 \mathrm{H}$ mice, and from $\mathrm{B} 6$ and $\mathrm{BALB} / \mathrm{cJ}$ mice, it was concluded that there is a major gene, designated Ath-1, which controls lesion development and HDL levels. The segregation patterns of these traits also tentatively suggested that the Ath-1 locus resides near the apolipoprotein A-II gene (Apoa2). This putative gene had to be distinct from Apoa2 since there were several apparent recombinants among the sets of RI strains (1). Subsequent to that proposal, more quantitative assessment of HDL levels and lesion development among the RI strains has suggested more complex patterns of inheritance $(31,32)$. Our present results suggest strongly that the Ath-1 gene does not reside on distal chromosome 1 and that, in fact, the inheritance of HDL-cholesterol levels on the atherogenic diet is multigenic, regulated by the loci on chromosomes 3,5 , and 11 . We examined aortic lesion size in all $185 \mathrm{~F} 2$ progeny and failed to observe suggestive evidence (lod $>2.5$ ) of linkage to markers on distal mouse chromosome 1 or elsewhere in the genome (data not shown). Given the large nongenetic variability of lesion development in this model, it is unlikely that genes explaining a small fraction of lesion susceptibility would have been revealed in this study, but a major gene (explaining most of the genetic variance in atherosclerosis) should have been identified. Studies with a congenic strain at the apoAII gene locus (18) and with apoAII transgenic mice (22) indicate that elevated apoAII expression increases HDL-cholesterol levels and that such apoAII rich HDL promotes atherosclerotic lesion development. Thus, the elevated HDL-cholesterol levels resulting from increased apoAII synthesis in mice carrying the $\mathrm{C} 3 \mathrm{H}$ allele would clearly not be responsible for protecting this strain from atherogenesis. Moreover, our results do not support the existence of a separate gene on distal chromosome 1 contributing to HDL levels. Recent studies indicate that susceptibility
A.

Chromosome 5

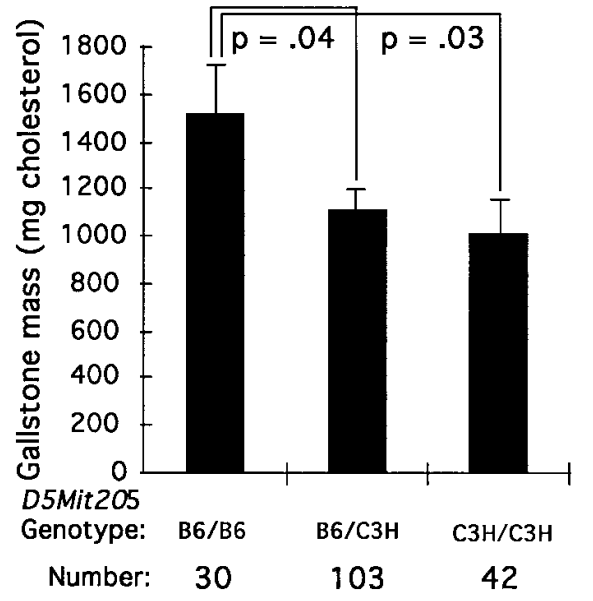

B.

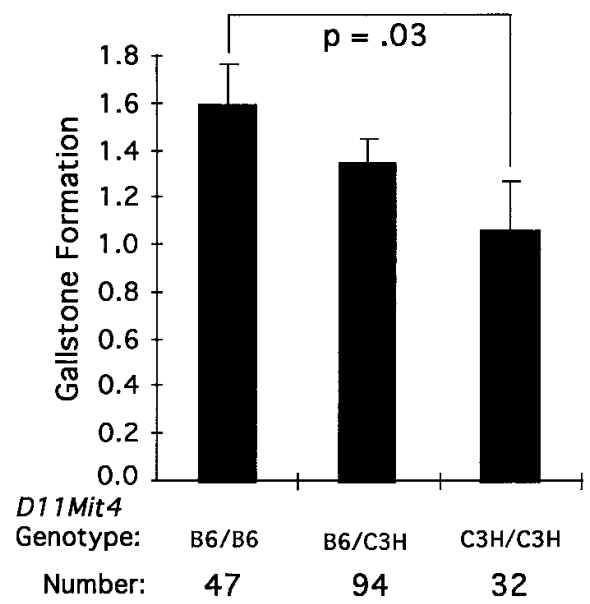

Figure 12. The effect of the loci on chromosomes 5 and 11 on gallstone mass and size. $(A)$ influence of marker D5Mit205 on gallstone mass measured by determining the amount of cholesterol in the gallstones. $(B)$ influence of marker D11Mit4 on the size of gallstones. The size of gallstones as estimated by visual inspection (see Methods). 
to atherogenesis in B6 mice is due in part to the activation of inflammatory genes and qualitative changes in the ability of HDL to protect against LDL oxidation (33), giving further support to the hypothesis for the multifactorial control of atherogenesis in this mouse model.

Genetic-dietary control of HDL metabolism. Our studies revealed several loci which specifically influence HDL-cholesterol levels in response to the atherogenic diet. These loci presumably explain the decrease in HDL-cholesterol in B6 mice challenged with the diet. The lod scores for the loci (2.5-3.4) were not sufficiently high to establish linkage conclusively, but the finding that three of the loci are coincident with loci for levels of C7AH mRNA provides strong support for their identity. A relationship between HDL metabolism and C7AH expression was suggested by the observation that cholic acid in the diet is required for the decrease in HDL-cholesterol in response to the diet. Moreover, we observed that the diet influenced $\mathrm{C} 7 \mathrm{AH}$ expression very differently in the $\mathrm{B} 6$ and $\mathrm{C} 3 \mathrm{H}$ strains (Fig. 8). None of the loci were linked to the $\mathrm{C} 7 \mathrm{AH}$ structural gene on chromosome 4, indicating that the loci must control $\mathrm{C} 7 \mathrm{AH}$ expression in trans. Candidate genes at the loci include certain transcription factors thought to contribute to C7AH expression (8) and to apolipoprotein expression (34-37). The locus on chromosome 4 mediating HDL levels in response to the diet resides near an interesting candidate, the leptin receptor gene $(d b)$; however, the $d b$ gene appears to be outside the $95 \%$ confidence interval at the locus. Conceivably, the loci could even contribute to differences in diet preference, which could influence food consumption and lipoprotein metabolism.

A mechanistic link between bile acid metabolism and lipoprotein metabolism. Several previous studies have suggested a link between the regulation of $\mathrm{C} 7 \mathrm{AH}$ and plasma lipoprotein metabolism. First, a genetic variant of the NZW rabbit strain that was relatively resistant to diet induced hypercholesterolemia also had an elevated level of C7AH expression (38). In addition, the susceptible rabbit strain, but not the resistant variant, showed a decrease in HDL cholesterol levels when challenged with a high fat diet, suggesting that the HDL levels are influenced by C7AH activity $(39,40)$. Second, the selectively bred RICO rat showed spontaneous hypercholesterolemia that was partially attributed to a reduced activity of C7AH (41). However, contrary to the susceptible NZW rabbit, the RICO rat showed elevated levels of both plasma $\beta$ VLDL and HDL cholesterol. Third, hamsters which were infected with a C7AH adenoviral construct exhibited 10- to 15 -fold higher levels of hepatic C7AH mRNA than hamsters infected with a control virus, and plasma levels of LDL as well as HDL decreased $60 \%$ and $50 \%$, respectively, as compared with levels in animals infected with a control virus (42).

A genetic link between bile acid metabolism and HDL metabolism. The inclusion of cholic acid in the atherogenic diet is required for the development of atherosclerotic lesions in B6 mice (43). In the absence of cholic acid, there is less accumulation of LDL/VLDL particles in the plasma and HDL-cholesterol levels either remain constant or increase (29). Originally, it was thought that the cholic acid facilitated the absorption of dietary cholesterol, but we observed little or no effect of cholic acid on cholesterol absorption (28). However, we did find that in B6 mice, the addition of cholic acid to the high fat diet resulted in a marked decrease in the expression of $\mathrm{C} 7 \mathrm{AH}$, at both the level of mRNA and enzyme activity. Conversely, the same diet lacking cholic acid resulted in an increase in expres- sion of C7AH (28). This suggested that the plasma lipoprotein changes observed in response to the atherogenic diet were mediated, in part, by an inhibition of bile acid synthesis.

There are at least two potential mechanisms by which expression of $\mathrm{C} 7 \mathrm{AH}$ could influence the levels of plasma lipoproteins and, in particular, HDL. The first involves a link between very low density lipoprotein (VLDL) synthesis and bile acid synthesis. Such as link has been observed in a variety of studies with bile acid sequestrants; thus, increased levels of bile acid production resulting from administration of drugs such as cholestyramine resulted in elevated $\mathrm{C} 7 \mathrm{AH}$ and increased VLDL production (44-46). This effect may be mediated by increased cholesterol production resulting from activation of the cholesterol biosynthetic pathway, in particular, hydroxymethylglutaryl-CoA (HMG-CoA) reductase, the rate limiting enzyme in the pathway (44). The enhanced VLDL synthesis would also be expected to result in increased production of HDL particles during lipolysis. Thus, if VLDL production parallels $\mathrm{C} 7 \mathrm{AH}$ expression in $\mathrm{C} 3 \mathrm{H}$ and $\mathrm{B} 6$ mice, $\mathrm{C} 3 \mathrm{H}$ mice would produce more VLDL and, hence, more HDL, than strain B6 mice. The failure to detect significant QTLs for VLDL/LDL levels coinciding with QTLs for C7AH levels could be due to increased expression of LDL receptor levels as a result of increased $\mathrm{C} 7 \mathrm{AH}$ activity. This is observed in humans in response to cholestyramine treatment (46).

The second potential mechanism relates to compartmentalization of cholesterol pools for bile acid synthesis and for secretion of cholesterol in the bile. The cholesterol for bile acids and biliary cholesterol appears to originate from different hepatic precursor pools. Bile acids are predominantly derived from free cholesterol that is synthesized de novo in the liver via the HMG-CoA reductase pathway, although some cholesterol derived from HDL also contributes to bile acid production. Under conditions where HMG-CoA reductase is repressed, the precursor pool for bile acids can still be maintained by an increased catabolism of HDL. The feeding of cholesterol and the bile acid taurocholate to rats suppresses HMG-CoA reductase activity, and this is concomitant with a two to threefold drop in plasma HDL cholesterol in rats (47). The B6 strain shows a particularly dramatic drop in activity of HMG-CoA reductase with the atherogenic diet which is accompanied by a two to threefold drop in plasma HDL cholesterol. The $\mathrm{C} 3 \mathrm{H}$ strain, on the other hand, exhibits significantly greater levels of HMG-CoA reductase activity than the B6 strain and their HDL-cholesterol levels do not drop with the atherogenic diet (48). If HMG-CoA reductase expression is in some manner regulated by $\mathrm{C} 7 \mathrm{AH}$ expression, as suggested by studies with cholestyramine administration (see above), strain B6 mice may have a greater dependence on HDL derived cholesterol for bile acid synthesis. How such dependence would be translated into increased HDL cholesterol uptake is unclear.

Recently, the construction and analysis of mice in which the $\mathrm{C} 7 \mathrm{AH}$ gene was disrupted by gene targeting were reported $(49,50)$. Although about half of the homozygous knockout mice died during the first three weeks of life, the surviving mice became healthier and showed a marked increase in survival, apparently due to a novel hepatic oxysterol 7 alpha hydroxylase enzyme activity which is developmentally induced about three weeks after birth. Importantly, these studies indicate that $\mathrm{C7AH}$ is not essential for the maintenance of serum cholesterol and triglyceride levels, although these results do not rule out possible quantitative effects of $\mathrm{C} 7 \mathrm{AH}$ on lipopro- 
tein metabolism (50). Thus, these studies suggest that $\mathrm{C} 7 \mathrm{AH}$ expression is unlikely to be a primary genetic determinant of HDL-cholesterol levels.

Gallstone formation. Strain B6 mice develop gallstones when maintained on the atherogenic diet whereas strain $\mathrm{C} 3 \mathrm{H}$ mice do not $(28,51)$. Our studies suggest that two of the loci contributing to $\mathrm{C} 7 \mathrm{AH}$ expression and HDL levels on an atherogenic diet also influence the formation of gallstones. Mechanistically, this is not unexpected since the ratio of cholesterol to bile acids appears to be a major determinant of gallstone formation (52). The balance of cholesterol and bile acids in the bile can be perturbed by alterations in the recycling of bile acids (53) as well as changes in dietary cholesterol (54) or the infusion of cholic acid (55). HDL-cholesterol is a source for biliary cholesterol and it is the biliary cholesterol which forms gallstones. Differences in the expression of $\mathrm{C} 7 \mathrm{AH}$ would likely influence the size of the bile acid pool which would alter the lithogenic index of the bile (56). This has been suggested in studies of gallstone patients shown to have a diminished bile acid pool size as well as a reduced rate cholic acid synthesis (57). Previous studies with RI strains have suggested the existence of a locus contributing to gallstone formation on mouse chromosome 2 (58). Our study involved different strains of mice and the genes which predispose to gallstone formation may differ between strains. Although our results require confirmation, they provide a possible animal model for the genetic contribution to gallstone disease in humans. It is noteworthy that the chromosome 5 locus but not the chromosome 11 locus was significantly linked to LDL/VLDL-cholesterol levels. This suggests that the loci may contribute to gallstone formation by distinct pathways or mechanisms. Further studies are required to address what components in the bile are affected by the diet as well as how the distributions of various bile acids are influenced by the diet.

\section{Acknowledgments}

We are grateful to Dr. Feng Liao and Mr. Carsten Nadjat Haiem for help in the initial steps of this project. We also thank Dr. Hungyu Zhao for his expertise in the statistical permutation analysis.

This work was supported by National Institutes of Health (NIH) grants HL-30568 and HL-42488.

\section{References}

1. Paigen, B., D. Mitchell, K. Reue, A. Morrow, A.J. Lusis, and R.C. LeBoeuf. 1987. Ath-l, a gene determining atherosclerosis susceptibility and high density lipoprotein levels in mice. Proc. Natl. Acad. Sci. USA. 84:3763-3767.

2. Paigen, B., B.Y. Ishida, J. Verstuyft, R.B. Winters, and D. Albee. 1990. Atherosclerosis susceptibility differences among progenitors of recombinant inbred strains of mice. Arteriosclerosis. 10:316-323.

3. Stewart-Phillips, J.L., J. Lough, and E. Skamene. 1989. Ath-3, a new gene for atherosclerosis in the mouse. Clin. Invest. Med. 12:121-126.

4. Nishina, P.M., J. Wang, W. Toyofuku, F.A. Kuypers, B.Y. Ishida, and B. Paigen. 1993. Atherosclerosis and plasma and liver lipids in nine inbred strains of mice. Lipids. 28:599-605.

5. Paigen, B. 1995. Genetics of responsiveness to high fat and high cholesterol diets in the mouse. Am. J. Clin. Nutr. 62:258S-462S.

6. LeBoeuf, R.C., M.H. Doolittle, A. Montcalm, D.C. Martin, K. Reue, and A.J. Lusis. 1990. Phenotypic characterization of the Ath-1 gene controlling high density lipoprotein levels and susceptibility to atherosclerosis. J. Lipid Res. 31: 91-101.

7. Purcell-Huynh, D.A., A. Weinreb, L.W. Castellani, M. Mehrabian, M.H. Doolittle, and A.J. Lusis. 1995. Genetic factors in lipoprotein metabolism: analysis of a genetic cross between inbred mouse strains NZB/BINJ and SM/J using a complete linkage map approach. J. Clin. Invest. 96:1845-1858.

8. Jelinek, D.F., S. Andersson, C.A. Slaughter, and D.W. Russell. 1990.
Cloning and regulation of cholesterol 7alpha-hydroxylase, the rate-limiting enzyme in bile acid biosynthesis. J. Biol. Chem. 265:8190-8197.

9. Wei, J.S., H.M. Huang, W.C. Shyu, and C.S. Wu. 1989. Simple enzymatic determination of total cholesterol in gallstones. Clin. Chem. 35:2247-2249.

10. Warden, C.H., J.S. Fisler, S.M. Shoemaker, P.-Z. Wen, K.L. Svenson, M.J. Pace, and A.J. Lusis. 1995. Identification of four chromosomal loci determining obesity in a multifactorial mouse model. J. Clin. Invest. 95:1545-1552.

11. Dietrich, W., H. Katz, S.E. Lincoln, H.-S. Shin, J. Friedman, N.C. Dracopoli, and E.S. Lander. 1992. A genetic map of the mouse suitable for typing intraspecific crosses. Genetics. 131:423-447.

12. Ivandic, B., J.-H. Qiao, D. Machleder, F. Liao, T. Drake, and A.J. Lusis 1996. A locus on chromosome 7 determines myocardial cell necrosis and calcification (dystrophic cardiac calcinosis) in mice. Proc. Natl. Acad. Sci. USA. 93: 5483-5488.

13. Manly, K.F. 1993. A Macintosh program for storage and analysis of experimental genetic mapping data. Mamm. Genome. 4:303-313.

14. Map Manager home page: http://mcbio.med.buffalo.edu/mapmgr.html

15. Lander, E.S., P. Green, J. Abrahamson, A. Barlow, M. Daley, S. Lincoln, and L. Newburg. 1987. MAPMAKER: an interactive computer package for constructing primary genetic linkage maps of experimental and natural populations. Genomics. 1:174-181.

16. Churchill, G.A., and R.W. Doerge. 1994. Empirical threshold values for quantitative trait mapping. Genetics. 138:963-971.

17. Welch, C.L., Y.-R. Xia, I. Shechter, R. Farese, M. Mehrabian, S. Mehdizadeh, C.H. Warden, and A.J. Lusis. 1996. Genetic regulation of cholesterol homeostasis: chromosomal organization of candidate genes. J. Lipid Res. 37: 1406-1421.

18. Mehrabian, M., J.-H. Qiao, R.H. Hyman, D. Ruddle, C. Laughton, and A.J. Lusis. 1993. Influence of the ApoA-II gene locus on HDL levels and fatty streak development in mice. Arterioscler. Thromb. 13:1-10.

19. Ott, J. 1991. Basic genetics and cytogenetics In Analysis of Human Genetic Linkage. Johns Hopkins University Press, Baltimore, MD. 10-17.

20. Lander, E.S., and N.J. Schork. 1994. Genetic dissection of complex traits. Science (Wash. DC). 265:2037-2048.

21. Doolittle, M.H., R.C. LeBoeuf, C.H. Warden, L.M. Bee, and A.J. Lusis. 1990. A polymorphism affecting apolipoprotein A-II translational efficiency determines high density lipoprotein size and composition. J. Biol. Chem. 265: 16380-16388

22. Warden, C. H., C. C. Hedrick, J.H. Qiao, L.W. Castellani, and A.J. Lusis. 1993. Atherosclerosis in transgenic mice overexpressing apolipoprotein A-II. Science (Wash. DC). 261:469-472.

23. Bain, P.A., M.H. Meisler, B.A. Taylor, and A. H. Payne. 1993. The genes encoding gonadal and nongonadal forms of $3 \beta$-hydroxysteroid dehydrogenase $/ \Delta^{5}-\Delta^{4}$ isomerase are closely linked on mouse chromosome 3. Genomics. 16:219-223.

24. McBride, M.W., A.J. Russell, K. Vass, V. Foster, S.M. Burridge, N. Morrison, E. Boyd, B.A.J. Ponder, and R.G. Sutcliffe. 1995. New members of the 3ß-hydroxysteroid dehydrogenase gene family. Mol. Cell. Probes. 9:121128.

25. Chiang, J.Y.L., and D. Stroup. 1994. Identification and characterization of a putative bile acid-responsive element in cholesterol 7 alpha-hydroxylase gene promoter. J. Biol. Chem. 269:17502-17507.

26. Cohen, J.C., J.J. Cali, D.F. Jelinek, M. Mehrabian, R.S. Sparkes, A.J. Lusis, D.W. Russell, and H.H. Hobbs. 1992. Cloning of the human cholesterol 7 alpha-hydroxylase gene (CYP7) and localization to chromosome 8q11-q12. Genomics. 14:153-161.

27. Mouse Genome Database. 1995. Mouse Genome Informatics Project. The Jackson Laboratory, Bar Harbor, ME. http://www.informatics.jax.org.

28. Dueland, S., J. Drisko, L. Graf, D. Machleder, A.J. Lusis, and R.A. Davis. 1993. Effect of dietary cholesterol and taurocholate on cholesterol 7 alpha-hydroxylase and hepatic LDL receptors in inbred mice. J. Lipid Res. 34: 923-931.

29. Lusis, A.J., B.A. Taylor, R.W. Wangenstein, and R.C. LeBoeuf. 1983. Genetic control of lipid transport in mice. II. Genes controlling structure of high density lipoproteins. J. Biol. Chem. 258:5071-5078.

30. Hedrick, C.C., L.W. Castellani, C.H. Warden, D.L. Puppione, and A.J. Lusis. 1993. Influence of mouse apolipoprotein A-II on plasma lipoproteins in transgenic mice. J. Biol. Chem. 268:20676-20682.

31. Liao, F., A. Andalibi, J.H. Qiao, H. Allayee, A.M. Fogelman, and A.J. Lusis. 1994. Genetic evidence for a common pathway mediating oxidative stress, inflammatory gene induction, and aortic fatty streak formation in mice. J. Clin. Invest. 94:877-884.

32. Hyman, R.W., S. Frank, C.H. Warden, A. Daluiski, R. Heller, and A.J. Lusis. 1994. Quantitative trait locus analysis of susceptibility to diet-induced atherosclerosis in recombinant inbred mice. Biochem. Genet. 32:397-407.

33. Shih, D.M., L. Gu, S. Hama, Y. Xia, M. Navab, A.M. Fogelman, and A.J. Lusis. 1996. Genetic-dietary regulation of serum paraoxonase expression and its role in atherogenesis in a mouse model. J. Clin. Invest. 97:1630-1639.

34. Hardon, E.M., M. Frain, G. Paonessa, and R. Cortese. 1988. Two distinct factors interact with the promoter regions of several liver-specific genes. EMBO (Eur. Mol. Biol. Org.) J. 7:1711-1719.

35. Meitus-Snyder, M., F.M. Sladek, G.S. Ginsburg, C.F. Kuo, J.A.A. 
Ladias, J.E. Darnell, Jr., and S.K. Karathanasis. 1992. Antagonism between apolipoprotien AI regulatory protein 1 Ear3/COUP-TF, and hepatocyte nuclear factor 4 modulates apolipoprotein CIII gene expression in liver and intestinal cells. Mol. Cell. Biol. 12:1708-1718.

36. Chan, J., H. Nakabayashi, and N.C.W. Wong. 1993. HNF-4 increases activity of the rat apo AI gene. Nuc. Acids Res. 21:1205-1211.

37. Zhong, W., J. Mirkovitch, and J.E. Darnell, Jr. 1994. Tissue-specific regulation of mouse hepatocyte nuclear factor 4 expression. Mol. Cell. Biol. 14: 7276-7284.

38. Poorman, J.A., R.A. Buck, S.A. Smith, M.L. Overturf, and D.S. LooseMitchell. 1993. Bile acid excretion and cholesterol 7 alpha-hydroxylase expression in hypercholesterolemia-resistant rabbits. J. Lipid Res. 34:1675-1685.

39. Overturf, M.L., S.A. Smith, A.M. Gotto, Jr., J.D. Morrisett, T. Tewson, J. Poorman, and D.S. Loose-Mitchell. 1990. Dietary cholesterol absorption, and sterol and bile acid excretion in hypercholesterolemia-resistant white rabbits. $J$. Lipid Res. 31:2019-2027.

40. Loose-Mitchell, D.S., J. A. Poorman, S.A. Smith, M.L. Overturf, J.D. Morrisett, and A.M. Gotto, Jr., M.R. Soma. 1991. Cholesterol metabolism in hypercholesterolemia-resistant rabbits. Atherosclerosis. 87:169-181.

41. Muller, K.R., J.R. Li, D.M. Dinh, and M.T. Subbiah. 1979. The characteristics and metabolism of a genetically hypercholesterolemic strain of rats (RICO). Biochim.Biophys. Acta. 574:334-343.

42. Spady, D.K., J.A. Cuthbert, M.N. Willard, and R.S. Meidell. 1995. Adenovirus-mediated transfer of a gene encoding cholesterol 7 alpha-hydroxylase into hamsters increases hepatic enzyme activity and reduces plasma total and low density lipoprotein cholesterol. J. Clin. Invest. 96:700-709.

43. Paigen, B., A. Morrow, C. Brandon, D. Mitchell, and P. Holmes. 1985. Variation in susceptibility to atherosclerosis among inbred strains of mice. Atherosclerosis. 57:65-73.

44. Carrella, M., S. Ericsson, C. Del Piano, B. Angelin, and K. Einarsson. 1991. Effect of cholestyramine treatment on biliary lipid secretion rates in normolipidaemic men. J. Int. Med. 229:241-246.

45. Einarsson, K., S. Ericsson, S. Ewerth, E. Reihner, M. Rudling, D. Stahlberg, and B. Angelin. 1991. Bile acid sequestrants: mechanisms of action on bile acid and cholesterol metabolism. Eur. J. Clin. Pharm. 40:S53-S58.

46. Reihner, E., B. Angelin, M. Rudling, S. Ewerth, I. Bjorkhem, and K. Einarsson. 1990. Regulation of hepatic cholesterol metabolism in humans: stimulatory effects of cholestyramine on HMG-CoA reductase activity and low density lipoprotein receptor expression in gallstone patients. J. Lipid Res. 31: 2219-2226.
47. Hueman, D.M., Z.R. Vlahcevic, M.L. Bailey, and P.B. Hylemon. 1988. Regulation of bile acid synthesis. II. Effect of bile acid feeding on enzymes regulating hepatic cholesterol and bile acid synthesis in the rat. Hepatology. 8:892897.

48. Hwa, J.J., S. Zollman, C.H. Warden, B.A. Taylor, P.A. Edwards, A.M. Fogelman, and A.J. Lusis. 1992. Genetic and dietary interactions in the regulation of HMG-CoA reductase gene expression. J. Lipid Res. 33:711-725.

49. Ishibashi, S., M. Schwarz, P.K. Frykman, J. Herz, and D.W. Russell. 1996. Disruption of cholesterol 7 alpha-hydroxylase gene in mice. I. Postnatal lethality reversed by bile acid and vitamin supplementation. J. Biol. Chem. 271: 18071-18023.

50. Schwarz, M., E.G. Lund, K.D.R. Setchell, H.J. Kayden, J.E. Zerwekh, I. Bjorkhem, J. Herz, and D.W. Russell. 1996. Disruption of cholesterol 7 alphahydroxylase gene in mice. II. Bile acid deficiency is overcome by induction of oxysterol 7 alpha-hydroxylase. J. Biol. Chem. 271:18024-18031.

51. Nishina, P.M., J. Verstuyft, and B. Paigen. 1990. Synthetic low and high fat diets for the study of atherosclerosis in the mouse. J. Lipid Res. 31:859-869.

52. Chijiiwa, K., I. Hirota, and H. Noshiro. 1993. High vesicular cholesterol and protein in bile are associated with formation of cholesterol but not pigment gallstones. Dig. Dis. Sci. 38:161-166.

53. Heaton, K.W., and A.E. Read. 1969. Gallstones in patients with disorders of the terminal ileum and disturbed bile salt metabolism. Br. Med. J. 3:494 496.

54. Nestel, P.J., and A. Poyser. 1976. Changes in cholesterol synthesis and excretion when cholesterol intake is increased. Metabolism. 25:1591-1599.

55. Lindblad, L., K. Lundholm, and T. Schersten. 1977. Influence of cholic and chenodeoxycholic acid on biliary cholesterol secretion in man. Eur. J. Clin. Invest. 7:383-388.

56. Ito, T., S. Kawata, Y. Imai, H. Kakimoto, J.M. Trazaskos, and Y. Matsuzawa. 1996. Hepatic cholesterol metabolism in patients with cholesterol gallstone: enhanced intracellular transport of cholesterol. Gastroenterology. 110: 1619-1627.

57. Vlahcevic, Z.R., C.C. Bell, Jr., I. Buhac, J.T. Farrar, and L. Swell. 1970. Diminished bile acid pool size in patients with gallstones. Gastroenterology. 59: 165-173.

58. Khanuja, B., Y-C. Cheah, M. Hunt, P.M. Nishina, D.Q.-H. Wang, H.W. Chen, J.T. Billheimer, M.C. Carey, and B. Paigen. 1995. Lith1, a major gene affecting cholesterol gallstone formation among inbred strains of mice. Proc. Natl. Acad. Sci. USA. 92:7729-7733. 